\title{
Ionic Mechanisms Underlying Repetitive High-Frequency Burst Firing in Supragranular Cortical Neurons
}

\author{
Joshua C. Brumberg, Lionel G. Nowak, and David A. McCormick \\ Section of Neurobiology, Yale University School of Medicine, New Haven, Connecticut 06510
}

Neocortical neurons in awake, behaving animals can generate high-frequency $(>300 \mathrm{~Hz}$ ) bursts of action potentials, either in single bursts or in a repetitive manner. Intracellular recordings of layer II/III pyramidal neurons were obtained from adult ferret visual cortical slices maintained in vitro to investigate the ionic mechanisms by which a subgroup of these cells generates repetitive, high-frequency burst discharges, a pattern referred to as "chattering." The generation of each but the first action potential in a burst was dependent on the critical interplay between the afterhyperpolarizations (AHPs) and afterdepolarizations (ADPs) that followed each action potential. The spikeafterdepolarization and the generation of action potential bursts were dependent on $\mathrm{Na}^{+}$, but not $\mathrm{Ca}^{2+}$, currents. Neither blocking of the transmembrane flow of $\mathrm{Ca}^{2+}$ nor the intracellular chelation of free $\mathrm{Ca}^{2+}$ with BAPTA inhibited the generation of intrinsic bursts. In contrast, decreasing the extracellular $\mathrm{Na}^{+}$ concentration or pharmacologically blocking $\mathrm{Na}^{+}$currents with tetrodotoxin, QX-314, or phenytoin inhibited bursting before inhibiting action potential generation. Additionally, a subset of layer II/III pyramidal neurons could be induced to switch from repetitive single spiking to a burst-firing mode by constant depolarizing current injection, by raising extracellular $\mathrm{K}^{+}$concentrations, or by potentiation of the persistent $\mathrm{Na}^{+}$current with the $\mathrm{Na}^{+}$channel toxin ATX II. These results indicate that cortical neurons may dynamically regulate their pattern of action potential generation through control of $\mathrm{Na}^{+}$and $\mathrm{K}^{+}$currents. The generation of high-frequency burst discharges may strongly influence the response of postsynaptic neurons and the operation of local cortical networks.

Key words: bursting; $\mathrm{Na}^{+}$currents; chattering cells; visual cortex; afterdepolarizations; afterhyperpolarizations
Cortical neurons in vivo frequently generate repetitive or single bursts of action potentials (Baranyi et al., 1993; Gray and McCormick, 1996). These bursts can occur with a relatively low intraburst frequency $(<300 \mathrm{~Hz})$ and be facilitated by slow wave sleep (Evarts, 1962, 1964), or they can occur with a higher intraburst frequency $(>300 \mathrm{~Hz})$ and be especially pronounced in the behaving animal (Gray and di Prisco, 1997). A subset of layer V pyramidal neurons generates intrinsic bursts of action potentials at $100-300 \mathrm{~Hz}$, and depolarization of these cells typically results in inhibition of these burst discharges (McCormick et al., 1985; Chagnac-Amitai et al., 1990; Mason and Larkman, 1990; Wang and McCormick, 1993). In contrast, another subset of cortical neurons, called "chattering" cells, can generate bursts with intraburst frequencies of $300-750 \mathrm{~Hz}$ and interburst frequencies of 10-80 Hz (Gray and McCormick, 1996; Steriade et al., 1998). The generation of repetitive burst discharges in these neurons is correlated with the generation of gamma frequency $(30-70 \mathrm{~Hz})$ oscillations in the local field potential (Gray and Singer, 1989). Although the functional consequences of burst discharges are not yet fully known, several studies have suggested that bursts may form a particularly powerful or relevant signal within cortical

Received Jan. 21, 2000; revised April 13, 2000; accepted April 14, 2000.

This work was supported by National Institute of Mental Health National Research Service Award F32MH12358-01 (J.C.B.) and National Eye Institute Grant 1-R01-EY12388 (D.A.M.). Additional information may be obtained at www. mccormicklab.org. Thanks to Hal Blumenfeld, Anita Luthi, and James Monckton for critical discussions and reviewing this manuscript.

Correspondence should be addressed to Dr. Joshua C. Brumberg, Section of Neurobiology, Yale University School of Medicine, 333 Cedar Street, New Haven, CT 06510. E-mail: brumberg@biomed.med.yale.edu.

Copyright (C) 2000 Society for Neuroscience $0270-6474 / 00 / 204829-15 \$ 15.00 / 0$ networks (Lisman, 1997; Snider et al., 1998) as well as within the bursting neuron itself (Helmchen et al., 1999).

The mechanisms of intrinsic bursting have been investigated in several different cell types (Llinas, 1988; Jensen et al., 1994; Traub et al., 1994; Azouz et al., 1996; Raman and Bean, 1997). Generally, burst firing is accomplished through the activation of either a subthreshold membrane conductance that initiates action potentials or a suprathreshold membrane conductance that once activated evokes two or more action potentials. Calcium-, $\mathrm{Na}^{+}$-, and $\mathrm{Ca}^{2+}$-activated conductances have all been implicated in burst generation. Hippocampal (Wong and Stewart, 1992; Traub et al., 1994) and layer V neocortical (Schwindt and Crill, 1999) pyramidal cells may initiate somatic $\mathrm{Na}^{+}$action potentials from a slow $\mathrm{Ca}^{2+}$ potential generated within the dendrites. Alternatively, bursts in subicular (Mattia et al., 1997) and sensorimotor cortical neurons (Franceschetti et al., 1995; Guatteo et al., 1996) may be generated through a voltage-dependent $\mathrm{Na}^{+}$conductance, independent of $\mathrm{Ca}^{2+}$. Intracellular recordings in vivo from chattering cells suggest that these bursts are generated through an unidentified suprathreshold mechanism initiated by the occurrence of action potentials (Gray and McCormick, 1996).

Importantly, the firing properties of some cortical neurons can convert from single spiking to burst generating after prolonged activation (Kang and Kayano, 1994; McCormick and Nowak, 1996). The ability of a neuron to change its output pattern could play a role in modulating synaptic efficacy, because bursts may be a mechanism by which cortical synapses become more reliable (Lisman, 1997).

In the present paper, the ionic mechanisms underlying both chattering and induced chattering in cortical neurons were studied using the ferret in vitro slice preparation. Results indicate that 
chattering, as well as induced bursting, is dependent on a sodium current and is calcium independent.

\section{MATERIALS AND METHODS}

Preparation of slices and solutions. Slices were obtained from 1- to 9-month-old male or female ferrets (Marshall Farms). The ferrets were deeply anesthetized with sodium pentobarbital $(30 \mathrm{mg} / \mathrm{kg})$ and decapitated. The brain was removed quickly, and the hemispheres were separated with a midline incision. Coronal slices of visual cortex were cut using a DSK microslicer (model DTK-1000, Ted Pella, Inc.). To maintain tissue viability, a modification of the technique developed by Aghajanian and Rasmussen (1989) was used. During the preparation of the cortical slices, the tissue was kept in a solution in which $\mathrm{NaCl}$ had been replaced with sucrose, and the osmolarity was maintained at $307 \mathrm{mOsm}$. After preparation, the slices were maintained in an interface style chamber (Fine Scientific Tools) and allowed to recover for at least $2 \mathrm{hr}$ at $34-36^{\circ} \mathrm{C}$. The bathing medium contained (in mM): $124 \mathrm{NaCl}, 2.5 \mathrm{KCl}, 2 \mathrm{MgSO}_{4}$, $1.25 \mathrm{NaH}_{2} \mathrm{PO}_{4}, 1.2 \mathrm{CaCl}_{2}, 26 \mathrm{NaHCO}_{3}, 10$ dextrose, and was aerated with $95 \% \mathrm{O}_{2}, 5 \% \mathrm{CO}_{2}$ to a final $\mathrm{pH}$ of 7.4 . For the first $10 \mathrm{~min}$ that the slices were in the recording chamber, the bathing medium contained an equal mixture of the bathing and slicing solutions with $2.0 \mathrm{mM} \mathrm{CaCl}_{2}$. After this incubation period, the slice solution was switched to medium containing $1.2 \mathrm{mM} \mathrm{CaCl}_{2}$.

Sharp microelectrodes were pulled from medium-walled glass (1BF100; WPI) on a Sutter Instruments P-80 micropipette puller and beveled on a Sutter Instruments beveler to a final resistance of 80-120 $\mathrm{M} \Omega$. Electrodes were filled with $2 \mathrm{M}$ potassium acetate (KAc) and sometimes with $1.5-2 \%(\mathrm{w} / \mathrm{v})$ biocytin for subsequent histological identification of recorded cells.

To investigate the intrinsic mechanisms of high-frequency burst discharge in cortical neurons, ionic substitutions and pharmacological manipulations were used. In experiments examining the role of calcium in burst generation, several strategies were used. First, calcium was replaced in the bathing solution by $2 \mathrm{mM} \mathrm{MnCl} 2\left(\mathrm{NaH}_{2} \mathrm{PO}_{4}\right.$ was also removed from the bathing solution to prevent precipitation). A second strategy was to backfill the tips of the intracellular microelectrodes with the calcium chelator BAPTA (Sigma, St. Louis, MO) in concentrations of either 50 or $100 \mathrm{~mm}$. Finally, the antiepileptic ethosuximide, which may reduce t-type $\mathrm{Ca}^{2+}$ channels, was added to the bathing solution $(5$ or $10 \mathrm{mM}$; Sigma).

The role of $\mathrm{Na}^{+}$currents in burst generation was investigated using similar strategies. First, $\mathrm{NaCl}$ was replaced in the bathing medium with $126 \mathrm{~mm}$ cholineCl (leaving $27.25 \mathrm{mM} \mathrm{Na}^{+}$). Second, $\mathrm{Na}^{+}$channels were blocked intracellularly using the quaternary lidocaine derivative QX-314 (10 mM in microelectrode; RBI, Natick, MA). Third, the $\mathrm{Na}^{+}$channel blocker tetrodotoxin (TTX, $1 \mu \mathrm{M}$; Sigma) was either bath-applied or applied using a puffer pipette (see below). Fourth, the $\mathrm{Na}^{+}$channel antagonist phenytoin was added to the bathing medium (120 $\mu \mathrm{M}$; Sigma). Finally, the sea anemone sulcata toxin, ATX II (50 $\mu \mathrm{M}$ in pipette mixed in slice solution without divalent cations) (Calbiochem, La Jolla, CA), was pressure-ejected using brief pulses of pressurized $\mathrm{N}_{2}(10-250 \mathrm{msec}$; $200-350 \mathrm{kPa})$ applied to the back end of a micropipette $(1-4 \mu \mathrm{m}$ tip diameter) positioned on the surface of the slice in close proximity to the recording microelectrode. Each pulse resulted in the ejection of $\sim 1-20 \mathrm{pl}$ of solution. ATX II acts specifically to impede sodium channel inactivation, trapping the $\mathrm{Na}^{+}$channel in a persistently conducting state (Romey et al., 1976; for review, see Alsen, 1983).

Intracellular recordings in vivo. To compare the electrophysiological properties of chattering cells in vitro with those obtained in vivo, these properties were measured in a few cells obtained from the primary visual cortex of halothane $/ \mathrm{N}_{2} \mathrm{O}$-anesthetized cats during the performance of other studies (Gray and McCormick, 1996).

Data collection and analysis. Our present in vitro recordings were confined to layer II/III of the visual cortex because previous in vivo studies have identified chattering cells as residing within these layers (Gray and McCormick, 1996). Initially, extracellular recordings were made using tungsten microelectrodes $(<1 \mathrm{M} \Omega$; Fredrick Hare Co. $)$ to determine both slice viability and the presence of chattering cells. Neocortical slices often have little spontaneous activity, and to search for the presence of chattering cells, the metabotropic glutamate agonist $(1 S, 3 R)$ 1-aminocyclopentane-1,3-dicarboxylic acid, (ACPD; Tocris Cookson Inc.) was pressure-applied (500 $\mu \mathrm{M}$ in pipette; see Fig. $1 A)$. The extracellular recordings were digitized onto VCR tapes for subsequent off-line analysis using the Spike 2 data collection software (Cambridge Electronic Design). The effect of ACPD application was transient (see Fig.
$1 A)$ and appeared to have no long-lasting influences on the cellular activity. Additionally, ACPD was only used in the initial extracellular experiments to determine the existence and percentage of chattering cells in different extracellular $\mathrm{Ca}^{2+}$ concentrations and in ferrets of different ages. Intracellular recordings were attempted only in those slices in which the extracellular recordings demonstrated the presence of a significant number of chattering neurons. Typically, these slices appeared to be "healthiest" in that they also exhibited a high density of neurons that generated relatively thin action potentials, similar to those recorded in vivo. Intracellular recordings were performed with an Axoclamp 2B intracellular amplifier (Axon Instruments). These recordings were digitized at $44 \mathrm{kHz}$ (Neuro-Corder DR-886, Neuro Data Instruments Corp.) and recorded to VCR tapes for subsequent off-line analysis.

Once a stable intracellular recording had been obtained (resting $V_{\mathrm{m}}$ of $-60 \mathrm{mV}$ or more negative, overshooting action potentials, ability to generate repetitive spikes to a depolarizing current pulse), the cell was classified, according to its discharge pattern to an injected current pulse, as either intrinsically bursting (intraburst frequency $<300 \mathrm{~Hz}$ ), regular spiking, fast spiking, or chattering (repetitive generation of two or more spikes per burst with an intraburst frequency of $>300 \mathrm{~Hz}$ ) (McCormick et al., 1985; Gray and McCormick, 1996). Intrinsically bursting neurons typically discharge a single burst of action potentials, followed by repetitive single spikes, whereas chattering cells burst repetitively during maintained depolarization. Spiking characteristics of chattering cells were measured off-line using the Spike2 data collection system or Axoscope 8.0 (Axon Instruments). Statistics were computed using either Statview (Abacus Concepts) or Microsoft Excel on a PC.

Histology. After a recording was complete, the slice was then fixed in $4 \%$ paraformaldehyde in $0.1 \mathrm{~m}$ phosphate buffer. Slices were subsequently placed in $20 \%$ sucrose in $0.1 \mathrm{M}$ phosphate buffer, sectioned on a freezing stage sliding microtome at $60 \mu \mathrm{m}$ thickness, and reacted using an ABC kit (Vector Laboratories, Burlingame, CA) (Horikawa and Armstrong, 1988). The sections were then mounted, dehydrated, defatted, and coverslipped using Permount mounting media. Sections were then observed using a Zeiss Axioplan2 microscope, and images were captured using a ProgRes camera and Adobe Photoshop (Adobe) on a Macintosh computer. The general morphological features of the filled cells, as well as their laminar locations, were then noted.

\section{RESULTS}

Although extracellular and intracellular recordings in vivo have previously described the presence and properties of a subgroup of neurons, called chattering cells, that generate high-frequency $(>300 \mathrm{~Hz})$ burst discharges composed of relatively short duration $(<0.6 \mathrm{msec}$ measured at half height) action potentials, these cells are not commonly found in slices of cerebral cortex maintained in vitro. One possible explanation of the low incidence of chattering cells in vitro is that the discharge mode of these cells depends critically on factors modified by the in vitro technique. Therefore, as a first step in the present study, we determined what conditions are required for the occurrence of chattering in vitro. For that purpose we performed a series of extracellular recording experiments (13 experiments, 315 single-unit recordings) while neurons were activated by local application by pressure ejection of the metabotropic glutamate receptor agonist ACPD (500 $\mu \mathrm{M}$ in the pipette). ACPD was used only for the experiments in which we assessed the frequency of chattering cells using extracellular recording techniques; ACPD was not used for any subsequent recording experiments.

Two differences between in vitro and in vivo studies were examined. The first was the age of the animal. Previous in vivo intracellular recordings of chattering cells were obtained from adult cats (Gray and McCormick, 1996; Steriade et al., 1998), whereas most in vitro studies make use of young animals. The second difference corresponds to differences in the ionic environment, especially concerning extracellular calcium concentration. The extracellular calcium concentration measured in brain interstitial fluid is $\sim 1.2 \mathrm{~mm}$ (Hansen, 1985), whereas, traditionally, in 

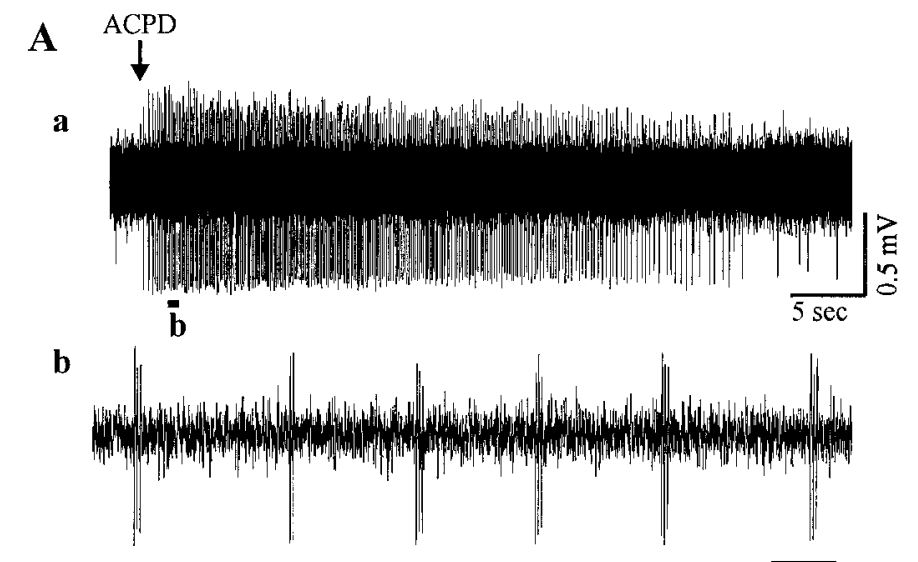

c

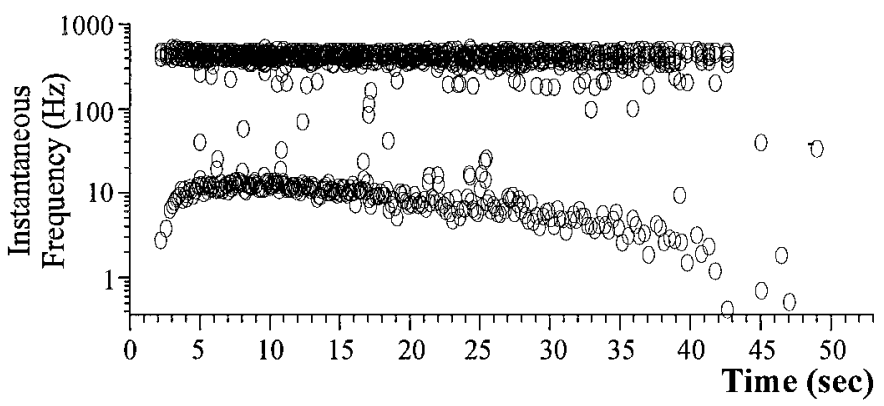

B

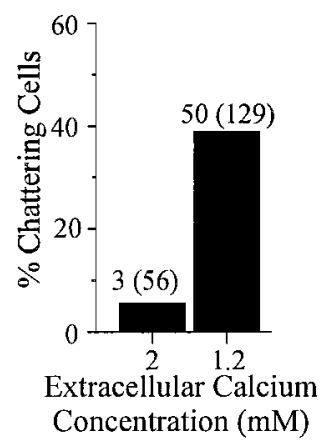

Figure 1. ACPD (500 $\mu \mathrm{M}$ in pipette) activates chattering cells in a previously quiescent slice $(A, a)$. Expanding the extracellular recording $(A, b)$ reveals high-frequency repetitive bursts. The interburst frequencies are the bottom data points in $A, c$, and the intraburst frequency of this is $>300 \mathrm{~Hz}$ (A,c, top traces). The developmental progression of the incidence of chattering is displayed in $C$. The bars represent the percentage of bursting neurons observed in the different aged animals or in $B$ how the incidence of chattering was affected by different concentrations of extracellular $\mathrm{Ca}^{2+}$. The numbers above the bars $(B, C)$ represent the number of chattering cells responsive to ACPD and the total number of units recorded.

vitro studies are performed with extracellular calcium concentration of $2 \mathrm{~mm}$ or more.

Figure $1 A, a$ shows a typical in vitro extracellular recording performed in a slice isolated from an adult ( $>3$ months) ferret and maintained in an ACSF containing $1.2 \mathrm{~mm}$ calcium. The application of ACPD induced firing in a previously silent cell. Closer examination of the response $(A, b$, expanded trace) reveals that the firing consisted of high-frequency bursts of two to three action potentials each. The graph in Figure $1 A, c$ represents the instantaneous firing frequency for the same cell and for the same epoch. Two frequency bands can be seen. The first one, which remains constant at $\sim 420 \mathrm{~Hz}$, corresponds to the intraburst frequency; the second one, between 1 and $11 \mathrm{~Hz}$, corresponds to the interburst frequency that increases and then slowly decreases in response to application of ACPD. Note that although the interburst frequency varies in the 10 -fold range, the intraburst frequency remains constant, a feature typical of chattering cells.

The incidence of high-frequency $(>300 \mathrm{~Hz})$ bursting neurons in the supragranular layers exposed to different calcium concentrations during the extracellular recording experiments performed in adult ( $>3$ months) animals is summarized in Figure $1 B$. High-frequency repetitive bursting neurons, using extracellular recording techniques, were observed in only $5 \%$ of the cells with $2 \mathrm{~mm}$ extracellular calcium; the incidence increased to $39 \%$ when $1.2 \mathrm{~mm}$ extracellular calcium concentration was used. The effect of calcium on the incidence of high-frequency bursting neurons is highly significant ( $\chi^{2}$ test, $\left.p<0.0001\right)$.

The age of the animal also had a profound effect on the probability of observing high-frequency bursting neurons. With $1.2 \mathrm{~mm}$ calcium concentration in the ACSF, no cell with burst frequency $>300 \mathrm{~Hz}$ could be observed in ferrets between 1 and 2 months old (Fig. 1C). In ferrets between 2 and 3 months old, the incidence of high-frequency bursting neurons was only $5 \%$, but it increased, as mentioned previously, to $39 \%$ for ferrets older than 3 months. The effect of age on the incidence of high-frequency bursting neurons is also highly significant ( $\chi^{2}$ test, $\left.p<0.0001\right)$.

High-frequency bursting neurons as described above may not be equated with chattering cells; instead, the high-frequency bursting observed could have been an effect of ACPD on neurons that otherwise would not have generated such bursts. Intracellular recordings in the absence of ACPD confirmed, however, that chattering cells were observed only in animals that were older than 3 months of age. Recordings from visual cortical slices obtained from ferrets that were between 2 and 3 months of age revealed regular spiking $(n=24)$, intrinsically bursting $(n=4)$, or fast spiking neurons $(n=1)$ but no chattering cells $\left(1.2 \mathrm{mM} \mathrm{Ca}^{2+}\right.$ used), whereas intracellular recordings from animals that were 4 months of age or older did confirm the presence of chattering cells (Fig. 2).

As a result, all subsequent experiments used visual cortical tissue obtained from ferrets that were at least 4 months old. In these conditions, and provided the ACSF contained only $1.2 \mathrm{~mm}$ calcium, chattering cells similar in all respects to those recorded in vivo (Fig. 3) could be recorded, although with intracellular recordings their incidence was lower than when using extracellular recording techniques (approximately only 4\% of neurons recorded from intracellularly were classified as chattering cells). It is unclear why chattering cells were less frequently encountered using intracellular recording techniques. We did find it more difficult to obtain stable recordings from chattering cells than regular spiking pyramidal cells. Similarly, interneurons are also encountered at frequencies lower than predicted based on the known cytology. One possibility is that the chattering state of action potential generation can be disrupted by the small leak associated with sharp electrode recording.

The effects of calcium may be related to the fact that decreasing extracellular $\mathrm{Ca}^{2+}$ increases excitability in neuronal tissue (Frankenhaeuser and Hodgkin, 1957; Hille 1968). Extracellular $\mathrm{Ca}^{2+}$ has been proposed to stabilize ionic pores within the membrane and screen charges in the vicinity of the plasma membrane (Hille, 1992). Thus decreasing extracellular $\mathrm{Ca}^{2+}$ renders the cells more excitable and perhaps more likely to "chatter." 
A
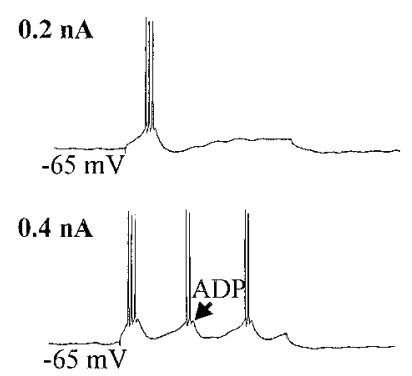

Figure 2. Response of a chattering cell to different amplitudes of current injection. Current pulses lasted $120 \mathrm{msec}$, and the amplitude of each pulse is to the left of each voltage trace $(A)$. Increasing the amplitude of the injected current pulse increases the interburst frequency $(B) . C$ plots the interburst frequency ( $y$-axis) as a function of the burst number $(x$-axis) for another neuron. The interburst frequency is lowest for the first interval and then shortens and reaches a plateau. This effect is independent of the intensity of the injected current $(D)$. Plotted are the interburst frequencies ( $y$-axis) of the first $(\bigcirc)$, second $(+)$, and third $(\boldsymbol{O})$ interburst intervals as a function of the strength of the injected current pulse ( $x$-axis). In every case the interburst interval is longest for the first interval, and there is no difference between the second and third intervals. Note the amplitude and time courses of the afterhyperpolarizations after a single burst $(A, 0.2 \mathrm{nA})$ and after repetitive burst firing $(A, 1.0 \mathrm{nA})$.

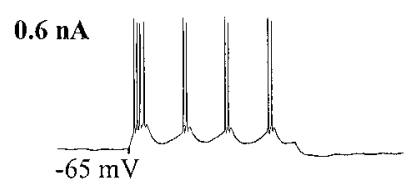

$1.0 \mathrm{nA}$

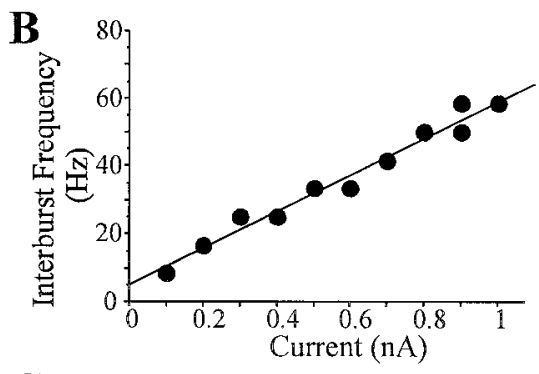

C
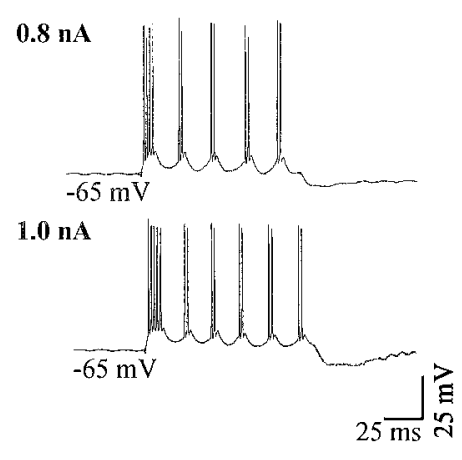

D
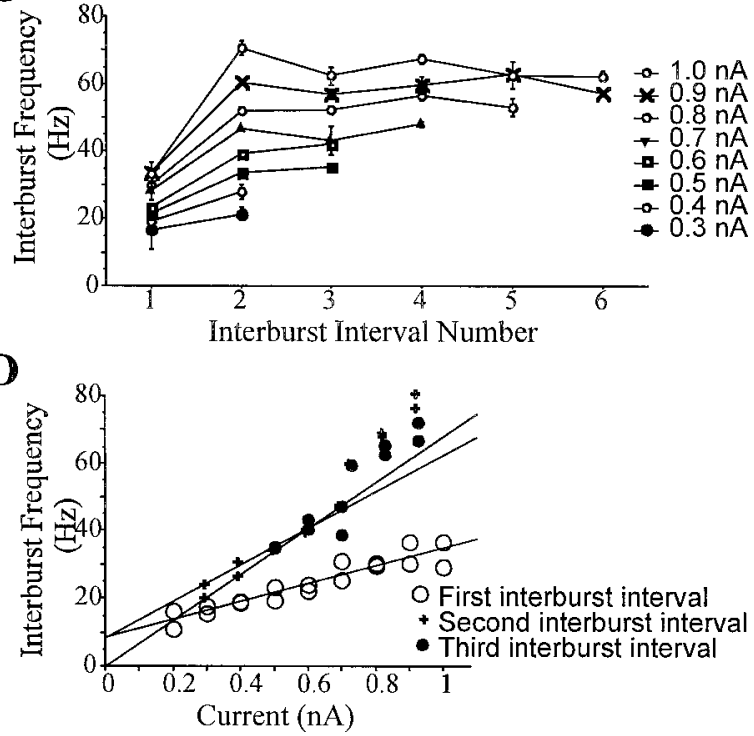

\section{Spiking characteristics of chattering cells}

Chattering neurons in vitro $(n=67)$ were characterized by the generation of repetitive high-frequency bursts of action potentials in response to the intracellular injection of depolarizing current pulses (Fig. $2 A$ ). This pattern of repetitive burst generation is different from the behavior of the intrinsic burst-generating (IB) pyramidal cells that are most often recorded in layer V. In IB cells a burst of action potentials typically occurs only once at the beginning of the pulse response and is followed by repetitive single action potential discharge (McCormick et al., 1985). Alternatively, these cells may generate repetitive bursts, but only at a relatively low interburst frequency of $<15 \mathrm{~Hz}$ (Agmon and Connors, 1989). One way to quantify the inactivation of burst discharge is to calculate the ratio of the number of bursts present in the first half of the pulse to the number of bursts for the whole pulse. For chattering cells as a population, this ratio was found to be $62 \pm 7 \%(n=11$, range $51-70 \%)$. For IB neurons recorded in layer II/III under the same conditions as for the chattering cells, this ratio averaged $98 \pm 4 \%(n=6$, range $89-100 \%)$.

Another defining characteristic of chattering cells is their high intraburst frequency. At the population level, the mean intraburst frequency is $400 \pm 57 \mathrm{~Hz}(n=11$, range $310-473 \mathrm{~Hz})$. This is considerably higher than for IB neurons $(166 \pm 36 \mathrm{~Hz}, n=6)$. Action potential width (measured at half height for the first action potential of the bursts) for chattering cells averages $0.40 \pm 0.11$ msec $(n=11$, range $0.21-0.54)$. This is significantly less $(t$ test, $p=0.03$ ) than the width obtained for regular spiking cells recorded in the same conditions $(0.53 \pm 0.15 \mathrm{msec}, n=15$, range 0.18-0.75), although the distribution of spike width for the two populations shows considerable overlap. The duration of action potentials in chattering cells was also significantly $(p=0.0015)$ less than spike width in IB neurons $(0.61 \pm 0.10 \mathrm{msec}, n=6$, range $0.45-0.69 \mathrm{msec})$.

The action potential height for chattering cells (measured from spike threshold, for the first spike of the burst) averaged $74 \pm 22$ $\mathrm{mV}$. This was not significantly different from action potential height for regular spiking (77 $\pm 6 \mathrm{mV} ; p=0.6$ ) or for IB neurons $(82 \pm 8 \mathrm{mV} ; p=0.4)$. In chattering cells, the amplitude of the first action potential within the burst is the largest, with subsequent action potentials having only slightly smaller amplitudes, attributable most likely to $\mathrm{Na}^{+}$channel inactivation. On average, the second action potential of the burst displayed a height $10 \%$ smaller than that of the first, owing to changes in both the maximal height of the action potential and a small increase in action potential threshold (Figs. 3A, 4A).

An important property of action potential generation in chattering neurons is that each action potential or burst of action potentials was followed by a fast afterdepolarization (ADP) (see below and Figs. 3, 4). A couple of cells showed features intermediate between bursting and chattering cells (see traces in Figs. $10 C, 12 A)$. Similarly to bursting neurons, these cells generate a burst of action potentials only at the beginning of the current pulse. However, these cells displayed spike width $(<0.5 \mathrm{msec})$ and intraburst frequency $(>300 \mathrm{~Hz})$ similar to those of chattering cells (these cells have not been included for the comparative statistics given above). Another feature of these cells was the prominent ADP that followed single action potential firing. These cells typically could be induced to chatter with steady depolarization, as described in the second part of Results (see below). 

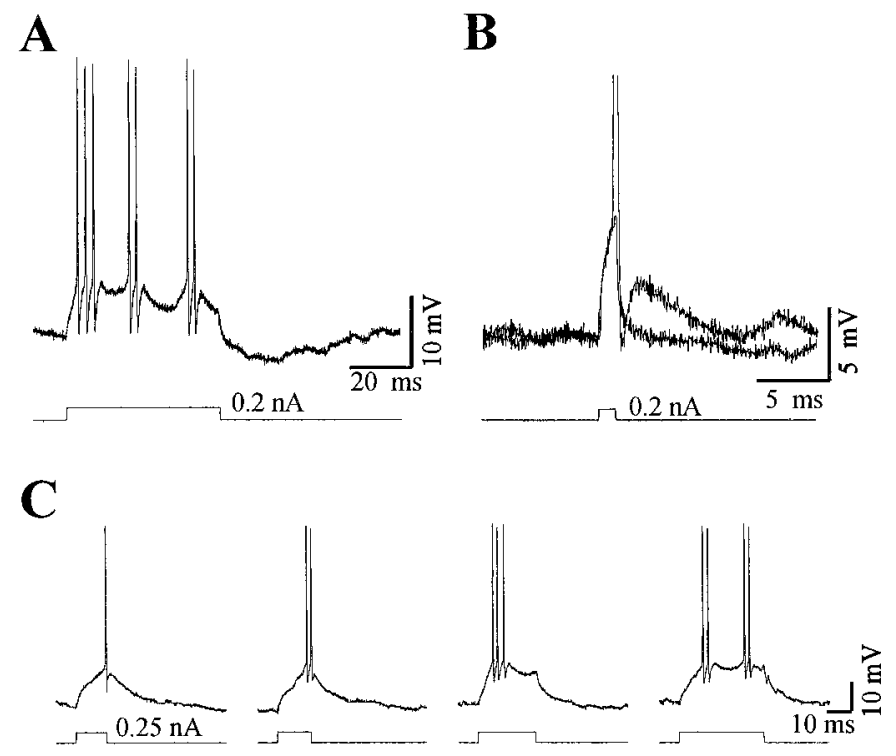

Figure 3. Properties of a chattering cell in the cat visual cortex in vivo. A, Intracellular injection of a depolarizing current pulse reveals repetitive burst firing at $71 \mathrm{~Hz}$. $B$, Intracellular injection of a short depolarizing current pulse results in the activation of a single action potential that exhibits a prominent fast afterhyperpolarization and afterdepolarization. Short depolarizing current pulses did not activate bursts of spikes that outlasted the duration of the current pulse. $C$, Increasing the duration of the current pulse resulted in the generation of bursts of action potentials and eventually in the generation of repetitive burst firing.

In chattering cells, increasing the intensity of the injected current pulse decreased the interburst interval and therefore increased the number of burst discharges ( $n=23$ of 23 chattering neurons tested). For the chattering cell shown in Figure $2 A$, the interburst frequency in response to a $+0.4 \mathrm{nA}, 120 \mathrm{msec}$ pulse was $25 \mathrm{~Hz}$ and at $+1.0 \mathrm{nA}$ it was $50 \mathrm{~Hz}$.

The burst frequency (for all bursts, averaged for each current intensity) as a function of current injected is illustrated for another cell in Figure 2B. For this cell the slope of the regression line is $54 \mathrm{~Hz} / \mathrm{nA}$. At the population level, the slope of the burst rate versus injected current was $58 \pm 23 \mathrm{~Hz} / \mathrm{nA}$ (range 30-116 $\mathrm{Hz} / \mathrm{nA}, n=11)$. According to the regression line obtained between current injected and burst frequency, the amount of current required to obtain a burst discharge at $40 \mathrm{~Hz}$ is $0.77 \pm$ $0.19 \mathrm{nA}$ (range $0.50-1.10 \mathrm{nA}$ ), which is well within the range of the net synaptic current that cortical cells receive during responses to visual stimuli (Ahmed et al., 1998).

Typically, the number of action potentials in the first burst is greater than the number of spikes in the next bursts (Fig. $2 A$ ). In general, the number of action potentials within a burst remains constant with increasing intensities of current injections. However, the number of action potentials in the first burst increased with increasing intensity of depolarizing current injected (Fig. 2A).

Interburst frequency versus current injected was also quantified for the successive bursts of the discharge (Fig. 2C,D). This analysis revealed that chattering cells did not show obvious adaptation in their burst discharge (Fig. 2C). In fact, we found that chattering cells displayed the opposite of adaptation, with the interburst frequency for the second interburst interval often being shorter than for the first. As a consequence, the slope for the first interburst frequency versus current injected is less steep than for the second or third (Fig. 2D). This was true also at the population
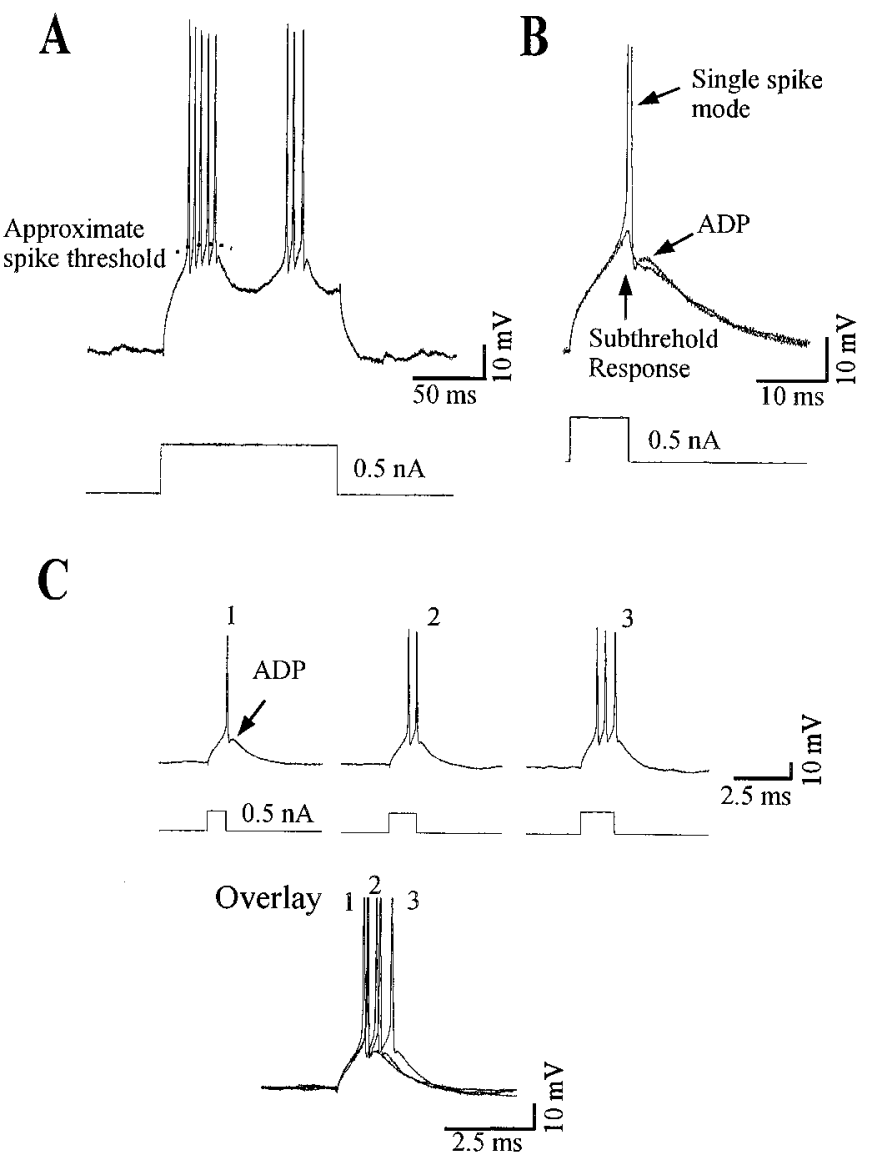

Figure 4. Properties of chattering cells in ferret visual cortex in vitro. A, Response of a chattering cell to a $120 \mathrm{msec}$ depolarizing current pulse $(0.5 \mathrm{nA})$. The dotted line indicates the approximate threshold for action potential initiation for each action potential within the burst. Note that the threshold assumes progressively more depolarized levels, and the burst is terminated when the ADP no longer exceeds threshold. Decreasing the duration of the current pulse duration at threshold evokes either single spikes or subthreshold responses $(B)$. Increasing the duration of the current pulse increases the number of action potentials in response, from one to three $(C)$. Overlaying the three traces suggests that the additional action potentials result from the activation of additional spikes by the ADP. Action potentials have been clipped in the overlay. Membrane potential is $-73 \mathrm{mV}$ for all three traces.

level, for which the first interburst frequency versus current slope $(43 \pm 22 \mathrm{~Hz} / \mathrm{nA})$ was less steep than the one for the second (62 \pm $27 \mathrm{~Hz} / \mathrm{nA})$ and third $(63.7 \pm 24 \mathrm{~Hz} / \mathrm{nA})$ interburst interval. When expressed as a ratio, the slope for the first interburst interval represented $64.7 \%$ that of the second interburst interval. The difference was found to be statistically significant (paired $t$ test, $p=0.001$ for first vs the second interburst, $p=0.005$ for first vs third interburst interval). One possible explanation for this behavior is the occurrence of a larger number of spikes during the first burst, compared with those that follow. This larger number could lead to a stronger activation of potassium currents that would slow down the burst firing rate (see Fig. 9).

Previous studies have demonstrated that spike frequency adaptation results from the activation of various $\mathrm{K}^{+}$currents, particularly a slow $\mathrm{Ca}^{2+}$-activated $\mathrm{K}^{+}$current that underlies the slow AHP (Storm, 1990). Chattering neurons did not exhibit a significant slow AHP after the cessation of a 120-500 msec duration depolarizing current pulse with repetitive bursts of action poten- 
tials. Rather, these cells exhibited an AHP of $5.28( \pm 1.68 ; n=9)$ $\mathrm{mV}$ in peak amplitude and $153.13( \pm 122.47) \mathrm{msec}$ in duration (Figs. 2A, 3A).

Another characteristic of chattering cells was their ability to discharge either a single action potential or bursts of action potentials depending on the duration of the intracellularly injected depolarizing current pulse, both in vivo (Fig. $3 C)(n=5)$ and in vitro (Fig. $4 C)(n=8)$. The initiation of the first action potential in these neurons appeared to arise from the passive charging of the membrane in response to the depolarizing current pulse (Figs. $3 A, B, 4 A, B$ ). Shortening the current pulse to $1-2$ msec resulted in the initiation of only single action potentials, and these spikes displayed a fast afterhyperpolarization (AHP) followed by a fast afterdepolarization (Fig. $3 B, C, 4 B, C$ ). This afterdepolarization appears to be actively generated and superimposed on the fast AHP, because the depolarizing phase of the fast AHP is much quicker than expected given the membrane time constant of these cells.

Increasing the duration of the depolarizing current pulses resulted in the afterdepolarization becoming suprathreshold for the generation of additional action potentials, until a burst of three to six spikes occurred (Figs. $3 C, 4 A, C$ ). Within a burst, each subsequent action potential was triggered at more depolarized levels (Fig. $4 A$, dashed line) until the burst was terminated by an ADP that did not exceed spike threshold. Further increases in the duration of the depolarizing current pulse did not further increase the number of action potentials, because the burst was terminated by an afterhyperpolarization. After this afterhyperpolarization, additional bursts could occur, given a depolarizing current pulse of sufficient duration (Figs. 3A, 4A). No return excitation or "reverberation" was observed in these cells after cessation of the depolarizing current pulse, indicating that the chattering state of action potential generation required maintained depolarization.

\section{Morphology of chattering cells}

All morphologically identified chattering cells $(n=5)$ were pyramidal neurons in layer II/III and exhibited spiny apical dendrites extending to layer I where a terminal tuft was formed, similar to chattering cells that were intracellularly labeled in vivo (Gray and McCormick 1996). With this small sample, chattering cells could not be easily differentiated from other pyramidal cells within the supragranular layers, including regular spiking neurons $(n=12)$ and cells that could be induced to chatter $(n=7)$. Fast spiking neurons that were morphologically identified $(n=3)$ were all nonpyramidal and possessed aspiny or sparsely spiny dendrites (data not shown).

\section{The subthreshold $I-V$ plot in chattering cells is relatively linear}

Unlike burst-generating thalamic neurons, chattering cells show little if any inward rectification or depolarizing "sag" in response to the intracellular injection of hyperpolarizing current pulses $(n=7)$. A series of membrane potential traces obtained in response to depolarizing and hyperpolarizing current pulses is presented in Figure $5 B$. The $I-V$ plot (Fig. $5 C$ ) indicates that the resistance measured at the beginning of the plateau of the voltage deflection is not significantly different from the one measured near the end of the current injection. These results suggest that chattering cells possess little, if any, of the time-dependent anomalous rectifier conductance known as $I_{\mathrm{AR}}$ or $I_{\mathrm{h}}$.

\section{Burst generation does not depend on calcium entry}

In many neuronal cell types, calcium plays an important role in shaping their discharge patterns. To investigate the role of calcium in burst generation in chattering cells, calcium was removed from the bathing solution and replaced with $2 \mathrm{mM} \mathrm{Mn}^{2+}(n=4)$. In all four cases the neurons continued to discharge bursts of action potentials, even after $\sim 1 \mathrm{hr}$ in the low $\mathrm{Ca}^{2+}$-containing solution (Fig. 6A,B). Removing extracellular $\mathrm{Ca}^{2+}$ also did not affect the fast AHP after each action potential (Figs. 6B,D). Similarly, in extracellular recordings of single chattering neurons, reducing the bath concentration of $\mathrm{Ca}^{2+}$ to $0.5 \mathrm{~mm}$ and raising $\mathrm{Mg}^{2+}$ to $8-10 \mathrm{~mm}$ also did not inhibit repetitive burst firing in putative chattering cells that were activated by ACPD or the muscarinic agonist acetyl- $\beta$-methylcholine $(n=4$; data not shown). However, decreasing extracellular calcium did affect the interburst interval, by lengthening it (Fig. 6, compare $A$ and $B$ ). From this data it does not appear that calcium has an essential role in the generation of burst discharges, because they, as well as the fast afterdepolarization after single action potentials, are still generated after the block of transmembrane $\mathrm{Ca}^{2+}$ conductances (Fig. 6A,B).

To further examine the role of $\mathrm{Ca}^{2+}$ in burst generation, recordings were made with microelectrodes filled with the calcium chelator BAPTA (either $50 \mathrm{~mm} ; n=9$; or $100 \mathrm{~mm}, n=2$ ) (Fig. $6 D, E)$. In no instance $(n=11)$ did BAPTA prevent the generation of burst discharges and spike ADPs. Similar to the 0 $\mathrm{mm} \mathrm{Ca}{ }^{2+}$ condition, chelating intracellular calcium led to an
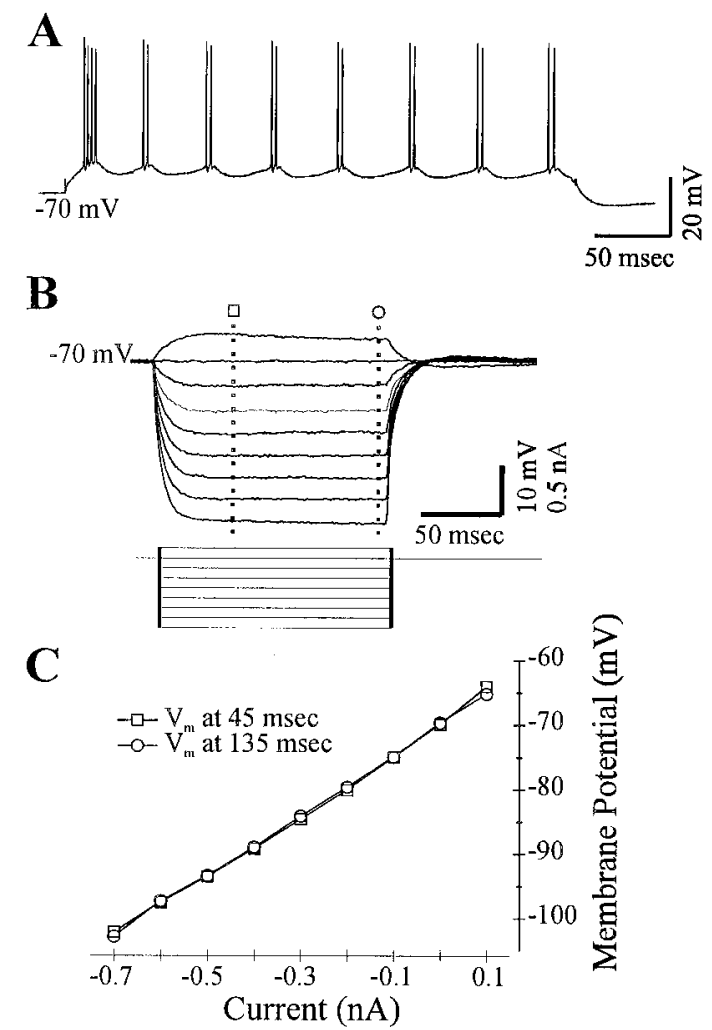

Figure 5. Chattering cells exhibit relatively linear membrane properties. $A$, The response of a supragranular chattering cell in response to a 300 msec $0.4 \mathrm{nA}$ depolarizing current pulse. $B$, The same cell as in $A$ in response to a family of hyperpolarizing and depolarizing current pulses. $C$, Plot of the membrane response at 45 and $135 \mathrm{msec}$ (see $B$ ) after the onset of the current pulses versus the amount of current injected. There is no evidence for substantial time- or voltage-dependent rectification. 
increase in the duration on the interburst interval after BAPTA had diff used into the neuron but did not affect spike duration or the fast spike afterhyperpolarization in chattering cells. In contrast, intracellular recordings in regular spiking neurons with electrodes containing BAPTA $(n=9)$ revealed a decrease in spike frequency adaptation and a broadening of the action potentials, confirming that this $\mathrm{Ca}^{2+}$ chelating agent was diff using into the neurons (data not shown) (Lancaster and Nicoll, 1987). Interestingly, fast spiking neurons that have action potentials with characteristics (rise times, width at half amplitude, rate of repolarization) similar to those of chattering cells also showed no effect due to the BAPTA manipulation $(n=2)$. Previous research has demonstrated neurons whose action potentials were also unaffected by BAPTA or similar $\mathrm{Ca}^{2+}$ manipulations in the hippocampus (Niesen et al., 1991; Pineda et al., 1998), the spinal cord (Zhang and Krnjevic 1988), and the neocortex (Schwindt et al., 1992; Chen et al., 1996). To account for this result, it was argued that the duration of the action potentials in these cells were too short for strong activation of $\mathrm{Ca}^{2+}$-dependent $\mathrm{K}^{+}$ currents, and therefore BAPTA, or the block of transmembrane $\mathrm{Ca}^{2+}$ currents, were without effect (Schwindt et al., 1992; Chen et al., 1996).

In thalamocortical neurons, bursts of action potentials are generated by low-threshold $\mathrm{Ca}^{2+}$ spikes (Llinas, 1988). To investigate whether a similar mechanism contributed to the generation of high-frequency bursting in chattering cells, the t-type $\mathrm{Ca}^{2+}$

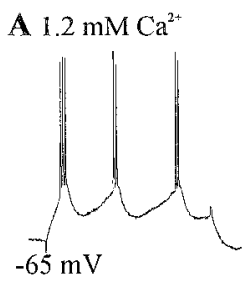

C $1.2 \mathrm{mMCa}^{2+}$

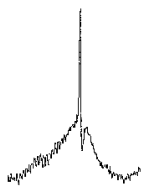

E Initial Response
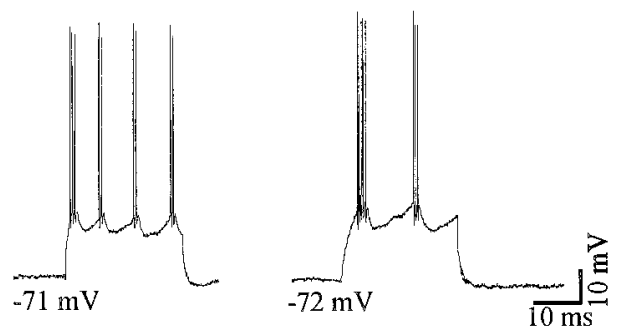

Figure 6. Transmembrane calcium entry is not essential to burst generation. Neither removal of $\mathrm{Ca}^{2+}$ from the bathing medium (compare $A, B$ ) nor chelation of intracellular $\mathrm{Ca}^{2+}$ by BAPTA (compare $E, F$ ) inhibited bursting. $A$ and $B$ represent a different cell than pictured in $E$ and $F$. Note that the interburst interval is lengthened due to both manipulations. Recordings obtained from another neuron reveal that ADPs are present in nominal $\mathrm{Ca}^{2+}$ in the bathing medium (compare $C, D$ ). In $C$ and $D$ the action potentials have been clipped to highlight the presence of the ADPs.
A $152 \mathrm{mMNaCl}$

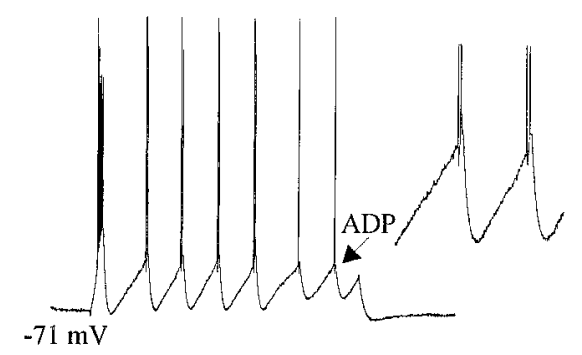

B 20 minutes $126 \mathrm{mM}$ Choline ${ }^{+}, 27.25 \mathrm{mM} \mathrm{Na}^{*}$

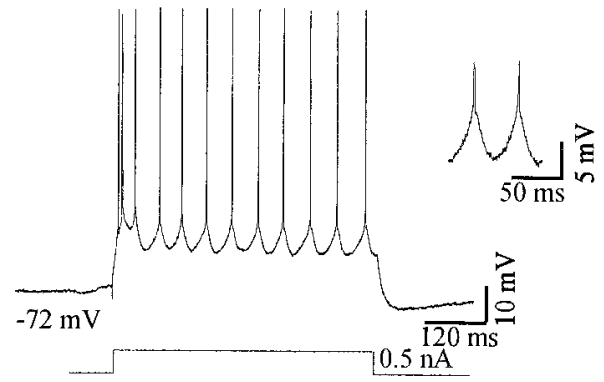

C Overlay

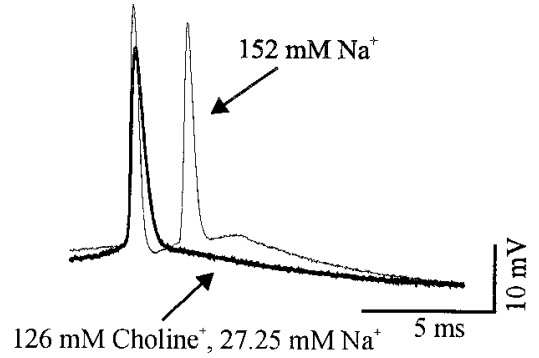

Figure 7. Decreasing the extracellular $\mathrm{Na}^{+}$concentration inhibits chattering. $A$, In normal bathing solution, intracellular injection of a depolarizing pulse results in repetitive doublets of action potentials and spike afterdepolarizations. $B$, Twenty minutes after replacement of $\mathrm{NaCl}$ with Choline $\mathrm{Cl}$, the repetitive doublets and the initial burst of action potentials are suppressed. $C$, Overlay of the action potentials before and during wash in low $\mathrm{Na}^{+}$reveals that the low $\mathrm{Na}^{+}$solution suppressed the spike ADP.

channel antagonist ethosuximide was added to the bathing solution while we recorded from chattering cells $(2 \mathrm{mM}, n=3 ; 5 \mathrm{~mm}$, $n=5 ; 10 \mathrm{~mm}, n=1)$. In all nine cases chattering was not inhibited by ethosuximide despite an order of magnitude range of concentrations. Taken together, these results implicate calcium as being important in the regulation of the interburst interval but not essential in the generation of burst discharges.

\section{Burst generation is dependent on $\mathrm{Na}^{+}$entry}

To study the role of $\mathrm{Na}^{+}$in burst generation, $\mathrm{NaCl}$ was replaced with equimolar cholineCl. As can be seen in Figure 7, chattering was inhibited in this neuron after 20 min of infusion of the choline $\mathrm{Cl}$ solution without abolishing action potential generation (Fig. 7, compare $A$ and $B)(n=2)$. Additionally, decreasing extracellular $\mathrm{Na}^{+}$decreased and eventually eliminated the ADP before action potential generation was inhibited (Fig. 7C). This result implicates a $\mathrm{Na}^{+}$current in the generation of the single spike ADP.

To further study the role of $\mathrm{Na}^{+}$in the generation of spike afterdepolarizations, neurons were recorded with electrodes 
A Initial Response

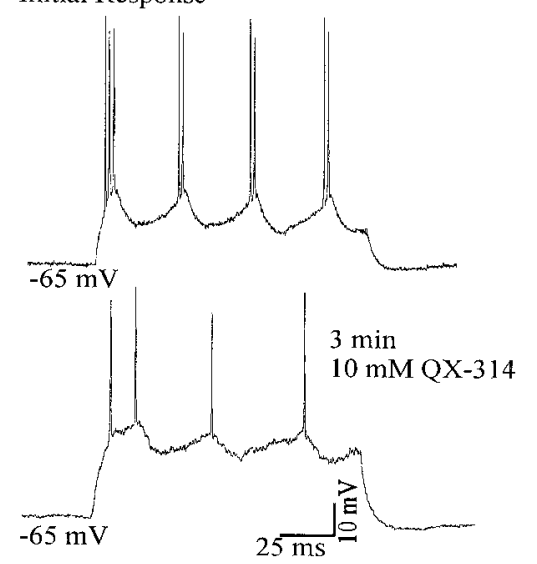

B Progressive action of TTX $(1 \mu \mathrm{M})$

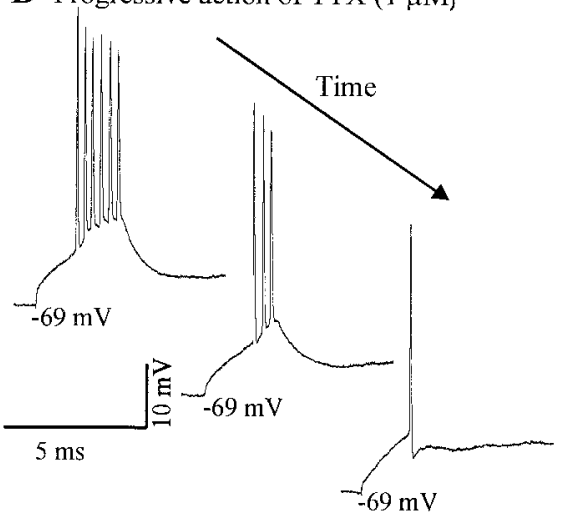

C Control
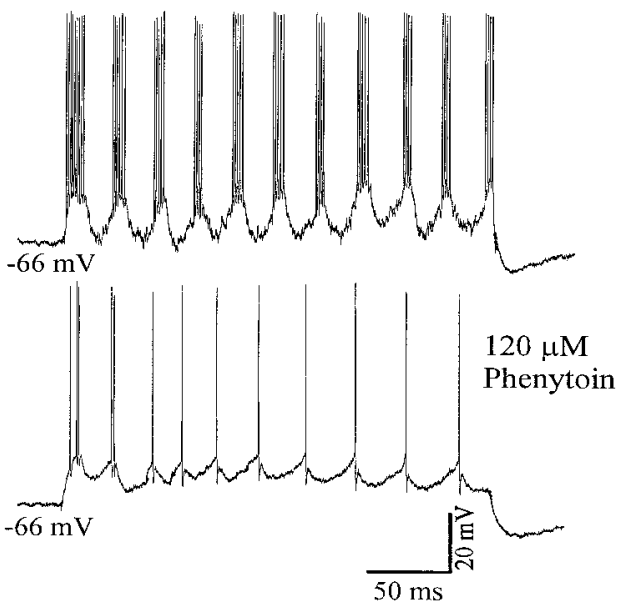

Figure 8. A persistent $\mathrm{Na}^{+}$current underlies chattering. $A$, Intracellular injection of a depolarizing pulse immediately after obtaining this intracellular recording revealed this cell to be a chattering neuron. After $3 \mathrm{~min}$ of recording with an electrode filled with $10 \mathrm{~mm}$ QX-314 (dissolved in 2 M KAc), the repetitive burst firing stopped before action potential generation was inhibited. Puffer application of TTX $(1 \mu \mathrm{M})$ inhibited bursting over time before blocking action potential initiation $(B)$. Bath application of the anti-epileptic phenytoin $(120 \mu \mathrm{M})$ also inhibited chattering $(C)$ in another neuron (current pulse was $+0.5 \mathrm{nA}$ ).

backfilled with the intracellular $\mathrm{Na}^{+}$channel blocker QX-314 (10 mM dissolved in $2 \mathrm{M}$ KAc). The effective concentration of QX-314 was determined initially by varying its concentration within the electrode from $1 \mu \mathrm{M}$ to $100 \mathrm{~mm} ; 10 \mathrm{~mm}$ was picked because it
A

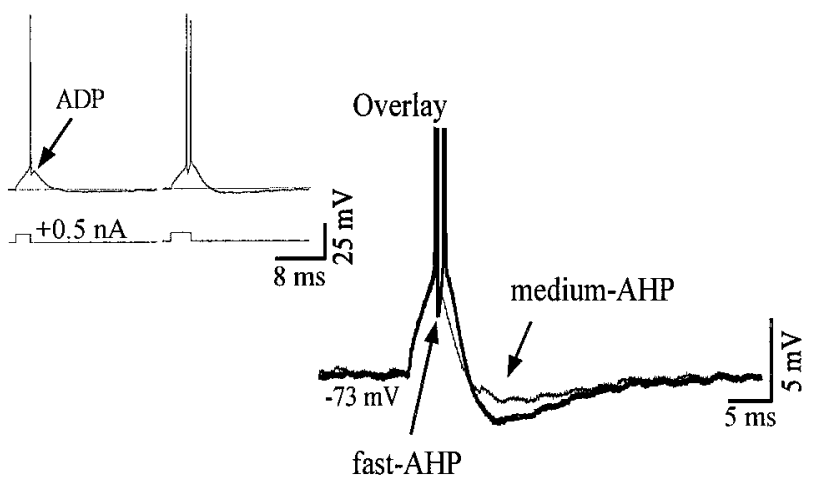

B

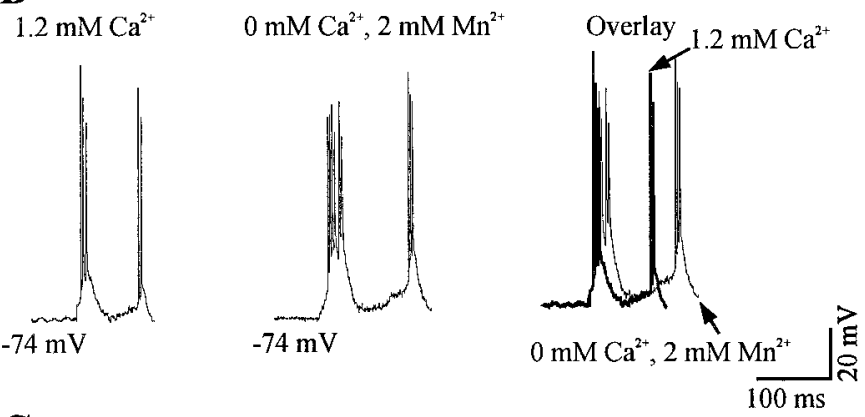

C

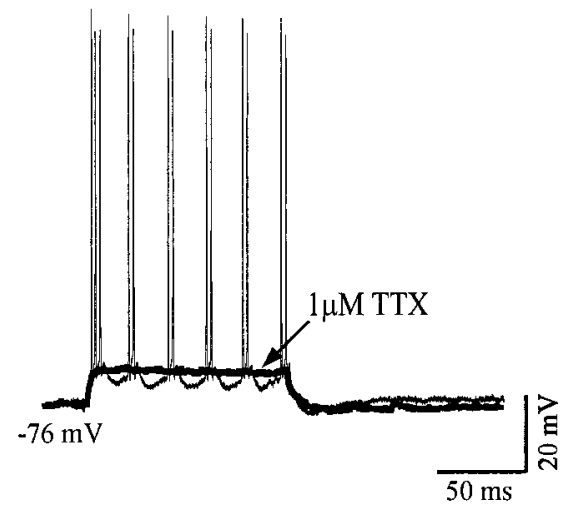

Figure 9. The interburst hyperpolarization is actively generated. $A$, Intracellular injection of a short depolarizing current pulse in a chattering cell generates either one or two action potentials with an increase in the duration of the pulse. Following the action potentials is a hyperpolarization that lasts for $\sim 20-30$ msec. $B$, Block of transmembrane $\mathrm{Ca}^{2+}$ currents with low $\mathrm{Ca}^{2+}$ and raised $\mathrm{Mn}^{2+}$ does not block the interburst AHP. $C$, Block of action potentials with tetrodotoxin reveals how the interburst AHP depends on the generation of a burst of action potentials.

inhibited action potential generation consistently after $12-15$ min, and this effect occurred slowly enough that the action on the spike ADP could be observed in regular spiking pyramidal cells that had relatively thin spikes followed by an ADP. QX-314 was generally effective ( $n=8$ of 11$)$ in reducing the amplitude of the ADP in these neurons before decreasing the number of action potentials evoked per $120 \mathrm{msec}$ depolarizing pulse $(+0.5 \mathrm{nA})$. The intracellular inf usion of QX-314 into chattering cells $(n=2)$ blocked the generation of repetitive burst discharges before the complete inhibition of action potentials (Fig. 8A). Additionally, the slow depolarizing potential on which the action potentials are initiated was reduced in amplitude by QX-314.

QX-314 modulates various channels in addition to $\mathrm{Na}^{+}$chan- 
Figure 10. Induction of chattering in a regular spiking neuron. $A-D$, Same data presented in increasingly fine detail by expanding the time base. $A$, Induction protocol. The spike discharge pattern was examined by injecting a $500 \mathrm{msec}$ duration depolarizing current pulse once every $2 \mathrm{sec}$ before and after constant depolarization for $16 \mathrm{sec} . B, C$, The neuron responds to the depolarizing current pulses with a train of single action potentials (except for a doublet at the beginning of the pulse) before tonic current injection. After current injection, the neuron now responds to the current pulse with the generation of repetitive bursts. Action potentials and their derivative reveal the presence of fast spike afterhyperpolarizations and afterdepolarization.

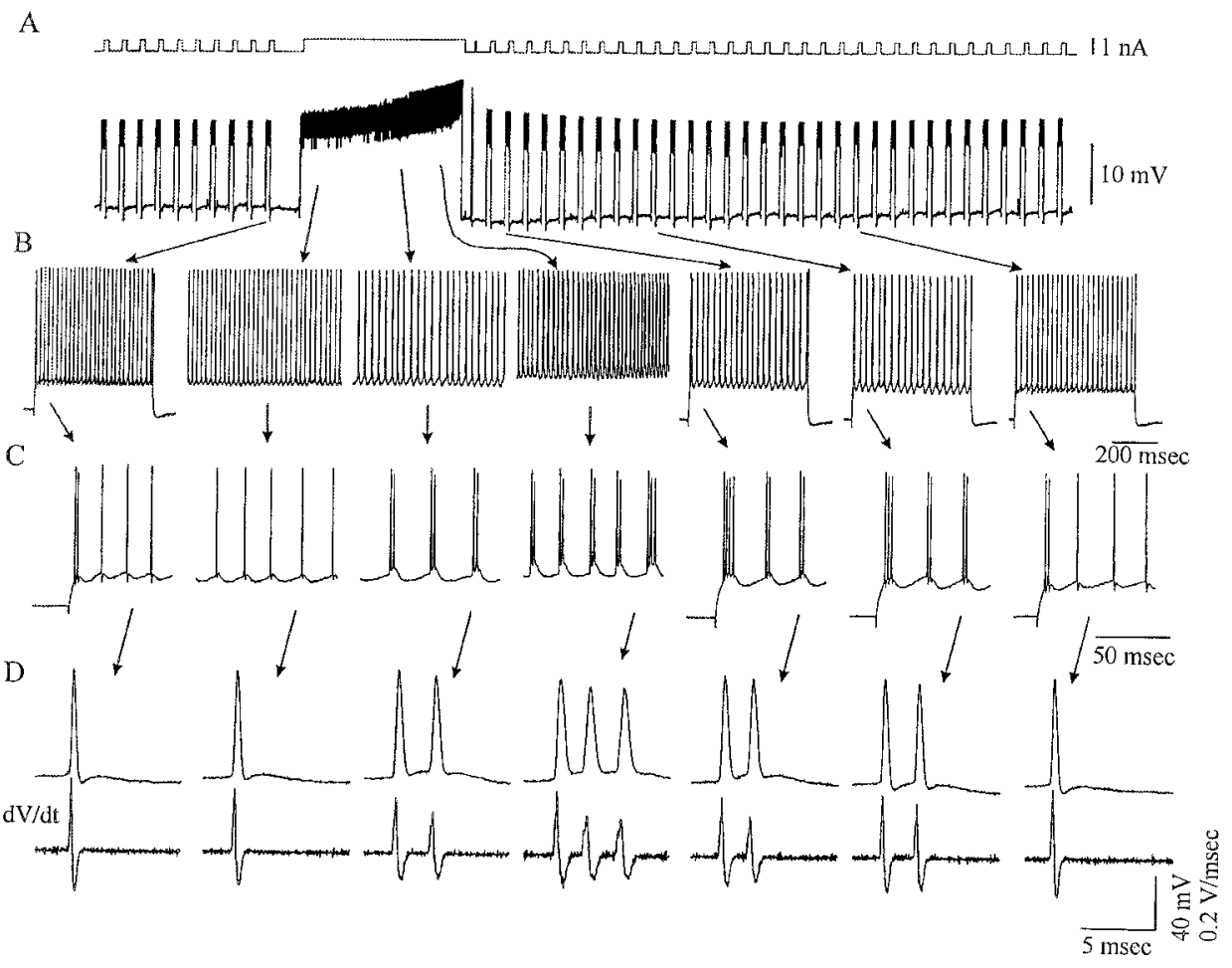

nels, such as calcium and potassium currents (Connors and Prince, 1982). As has been demonstrated in this study, reducing $\mathrm{Ca}^{2+}$ flux does not affect the burst properties of chattering cells. QX-314 also effects the flicker $\mathrm{K}^{+}$channel (Brau et al., 1995) as well as the $\mathrm{GABA}_{\mathrm{B}}$-dependent $\mathrm{K}^{+}$current (Nathan et al., 1990), both of which are unlikely to play a role in the bursting behavior of these cells. Additionally, QX-314 modulates the hyperpolarizationactivated cation current, $I_{\mathrm{h}}$ (Perkins and Wong, 1995), but based on the lack of a major sag in response to hyperpolarizing current pulses (Fig. 6B), this does not appear to invalidate the reported result. Thus it appears likely that the inhibition of bursting by QX-314 is attributable to its effects only on $\mathrm{Na}^{+}$currents. Similarly, either bath or puffer application of the $\mathrm{Na}^{+}$channel blocker TTX $(1 \mu \mathrm{M})$ initially inhibited bursting (Fig. $8 B$ ), resulting in the neuron responding with a train of single action potentials in response to a depolarizing current pulse ( $n=3$ of 3 ). Subsequently, action potential initiation was completely blocked.

The role of sodium in the generation of chattering behavior was further examined using bath application of the anti-epileptic phenytoin $(n=3)$. Phenytoin decreases neuronal excitability by modulating $\mathrm{Na}^{+}$currents, specifically by decreasing the persistent $\mathrm{Na}^{+}$current (Chao and Alzheimer, 1995; Segal and Douglas, 1997). Bath application of $120 \mu \mathrm{M}$ phenytoin inhibited the chattering mode of action potential generation before inhibiting the generation of action potentials (Fig. $8 C$ ). The action of phenytoin was not attributable to just an overall decrease in cell excitability, because even stronger depolarizing pulses $(>0.5 \mathrm{nA})$ could not evoke repetitive bursts $(n=3$ of 3$)$.

\section{The interburst interval is generated by an afterhyperpolarization}

The cessation of action potential generation in a burst occurs when the spike fast afterdepolarization does not reach action potential threshold. After the generation of a burst of spikes there is an afterhyperpolarization that appears to be actively gener- ated, because it hyperpolarizes the membrane potential below its resting level (Figs. $2 A, 9 A, C$ ) and becomes increasingly larger with increasing numbers of action potentials (Figs. $7 A, 9 A$ ). Block of action potential generation with QX-314 included in the recording microelectrode $(10 \mathrm{mM})$ or bath application of tetrodotoxin $(1 \mu \mathrm{M})$ revealed that AHP was also an active process at more depolarized membrane potentials (Fig. $9 C)(n=3)$. Although the ionic mechanisms of this afterhyperpolarization were not examined, it is most likely generated by a $\mathrm{K}^{+}$current (Chen et al., 1996). The persistence of this AHP in $0 \mathrm{mM} \mathrm{Ca}^{2+}$ medium and after BAPTA infusion suggests that it is not critically dependent on $\mathrm{Ca}^{2+}$-activated $\mathrm{K}^{+}$currents for its generation. It is unlikely that the hyperpolarization-activated cation current $I_{\mathrm{h}}$ plays a significant role in the generation of this afterhyperpolarization (McCormick and Pape, 1990), because chattering cells do not exhibit time-dependent inward sag on hyperpolarization (Fig. 5), and the AHP occurs at depolarized as well as hyperpolarized levels.

\section{Repolarizing phase of the chattering cell action potential}

Examination of the derivative of the action potential waveforms revealed that the peak rate of repolarization of the chattering cell action potential $(201.05 \pm 19.19 \mathrm{~V} / \mathrm{sec}, n=11)$ is faster than that of regular spiking neurons $(153.04 \pm 23.82 \mathrm{~V} / \mathrm{sec}, n=15)$ but not significantly so ( $t$ test, $p>0.05$ ). Computing the ratio of the peak rate of rise to the peak rate of fall for chattering cells $(3.09 \pm 0.04$, $n=11)$ and regular spiking neurons $(3.93 \pm 0.02, n=15)$ reveals a significant difference ( $t$ test, $p<0.03$ ). The repolarizing phase of the chattering cell action potential was sensitive to bath application of TEA ( $1 \mathrm{~mm}, n=2 ; 5 \mathrm{~mm}, n=3)$ but was not sensitive to bath application of the A-type $\mathrm{K}^{+}$channel antagonist 4-AP (5 $\mathrm{mm}, n=3)$. Although preliminary, these results suggest that a fast non-A-type $\mathrm{K}^{+}$current may mediate the repolarizing phase of 
A Overlay: control and induction $\mathbf{B}$ Overlay: recovery at beginning, middle and end

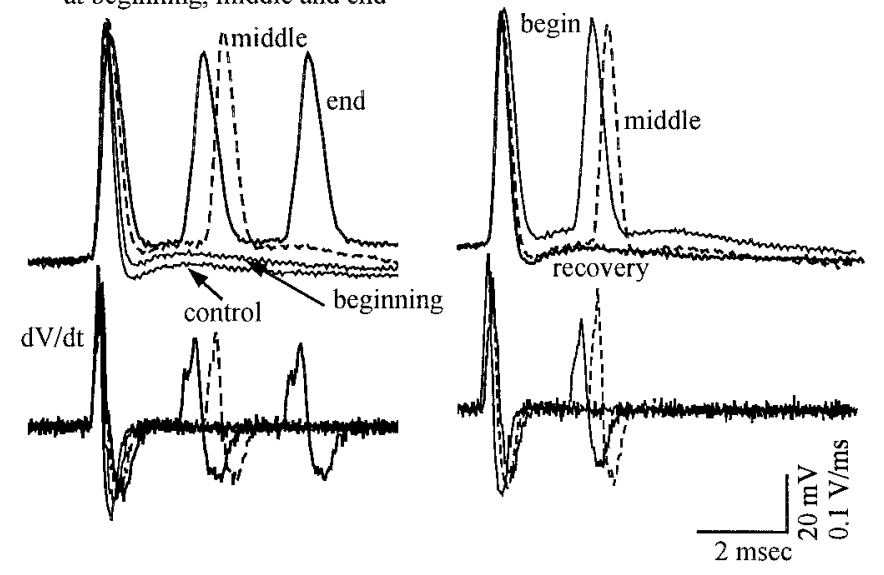

Figure 11. Overlay of action potentials before, during, and recovery from induced repetitive bursting. $A$, Overlay of the four traces in Figure $10 D$ before and during induction reveals the action potentials to become broader in duration and a marked decrease in the fast spike afterhyperpolarization. Subsequently, the fast afterdepolarization is able to generate additional action potentials. $B$, During recovery from chattering induction, the action potential returns to its original duration and the fast afterhyperpolarization returns.

the chattering cell action potential, as recently suggested for fast spiking interneurons (Erisir et al., 1999).

\section{Induction of rhythmic burst discharges}

In 20 regular spiking neurons, the injection of a prolonged (300$1000 \mathrm{msec}$ ) depolarizing current pulse resulted in a train of single action potentials that exhibited relatively little spike frequency adaptation. In addition, in these cells, each action potential was followed by a fast AHP and a prominent ADP (Fig. 10D). Using several different manipulations, neurons with these spiking characteristics could be induced to discharge bursts of action potentials (Fig. 10). Four different protocols were used to switch a neuron from discharging trains of single action potentials to rhythmic bursts of action potentials (chattering): (1) intracellular injection of constant depolarizing current $(\sim 1.0 \mathrm{nA})$ for $15-60$ sec; (2) intracellular injection of $30+1.0$-nA step pulses (500 msec duration); (3) raising of extracellular $\mathrm{K}^{+}$from 2.5 to 5.0 mM; and (4) potentiation of the persistent $\mathrm{Na}^{+}$current by the extracellular application of the sea anemone toxin ATX II.

\section{Current injection induces rhythmic bursting}

Intracellular injection of constant depolarizing current (approximately $+1.0 \mathrm{nA}$ ) for $15-60 \mathrm{sec}$ converted a subset of neurons from repetitive single action potential discharges to the generation of repetitive doublets or triplets (bursts) of action potentials $(n=10)$ (Figs. 10, 11). Three characteristics appeared to be important for a neuron to be able to be converted in this manner: a relatively short duration action potential (width at half height $<0.7 \mathrm{msec}$ ), and the generation of a fast AHP and a fast ADP after each action potential (Figs. 10, 11). The generation of a prolonged $(15-60 \mathrm{sec})$ period of action potentials through the injection of depolarizing current results in a broadening of the action potential by slowing the repolarizing phase (see below), allowing the spike ADP to become suprathreshold for the activation of an additional spike (Figs. 10,11). After the induction procedure, the threshold for action potential initiation was at a more depolarized level for the first spike within the burst, and subsequent action potentials within the burst had thresholds at even more depolarized levels (paired $t$ tests, $p$ values $<0.05$ ). Additionally, there was no observable change in $R_{\text {in }}$ before versus after induction (paired $t$ tests, $p$ values $>0.05$ ). In control experiments, neither regular spiking neurons with spike width at half amplitude $>0.8 \mathrm{msec}(n=16)$ nor fast spiking presumed interneurons $(n=4)$ were convertible by constant depolarizing current injections.

Step pulses similar to those used by Kang and Kayano (1994) and of the same magnitude as the constant depolarizing current $(+1.0 \mathrm{nA})$ could also induce repetitive doublet or triplet discharge $(n=11)$. Comparing the two protocols revealed that neurons that were able to be induced to burst with constant current were also inducible with the injection of 30500 -msec pulses delivered at $1 \mathrm{~Hz}(n=9$ of 9$)$, and the results of induction with step pulses were indistinguishable from those using constant depolarizing current. Following either the constant current or step pulse induction protocols, the repetitive bursting mode lasted for 30-60 sec before recovery to discharging trains of single action potentials (Fig. 10). The repetitive bursting mode was characterized by an initial discharge of three to four action potentials followed typically by repetitive doublets (Figs. 10, 12, 13). In many instances the induced bursting resembled the discharges observed in similar current pulses in chattering cells, but several neurons after induction had $<300 \mathrm{~Hz}$ intraburst spike frequencies. For purposes of analysis, all induced neurons were considered equivalent.

Closer examination of the action potentials and the first derivative of their voltage revealed that induction of repetitive bursting was associated with a striking loss of the fast afterhyperpolarization, which allowed the afterdepolarization after each action potential to initiate additional spikes (Figs. 10D, 11A). In addition, induction of repetitive bursting was associated with a broadening of the action potential and a decrease in the maximal rate of fall of each spike. Quantitative analysis revealed that the spike widths of the action potentials after induction $(0.64 \pm 0.14 \mathrm{msec})$ of rhythmic bursting were significantly broader than the preinduction action potential $(0.5 \pm 0.12 \mathrm{msec}$, paired $t$ tests, $n=8, p$ values $<.05)$. Recovery from induction was associated with a reversal of these effects (Figs. $10 D, 11 B$ ). Thus it appears that induction of repetitive burst firing results from a loss of the fast afterhyperpolarization, which broadens the action potential and allows the unmasking or further expression of a slow inward current underlying the ADP. The result of these two phenomena is that when the membrane repolarizes it reaches a more depolarized level that is still above threshold, and thus an additional action potential is generated and bursting is induced.

Interestingly, during the induction procedure, the derivative of the action potential revealed two distinct phases of rapid upswing during the rising phase of the action potential (Fig. 11A). Closer examination of the action potentials revealed that the transition between these two phases appeared as a "hump" on the rising phase of the action potential (data not shown). Indeed, we often noted with intracellular recordings that when chattering cells deteriorate, their action potentials fractionate into two active components, with the small component being generated first (data not shown). These results suggest that the action potentials in chattering cells are generated in at least two compartments, presumably being initiated in the initial segment of the axon, followed by propagation and generation of the action potentials in soma and/or dendrites (Stuart and Sakmann, 1994; Stuart et al., 1997). 


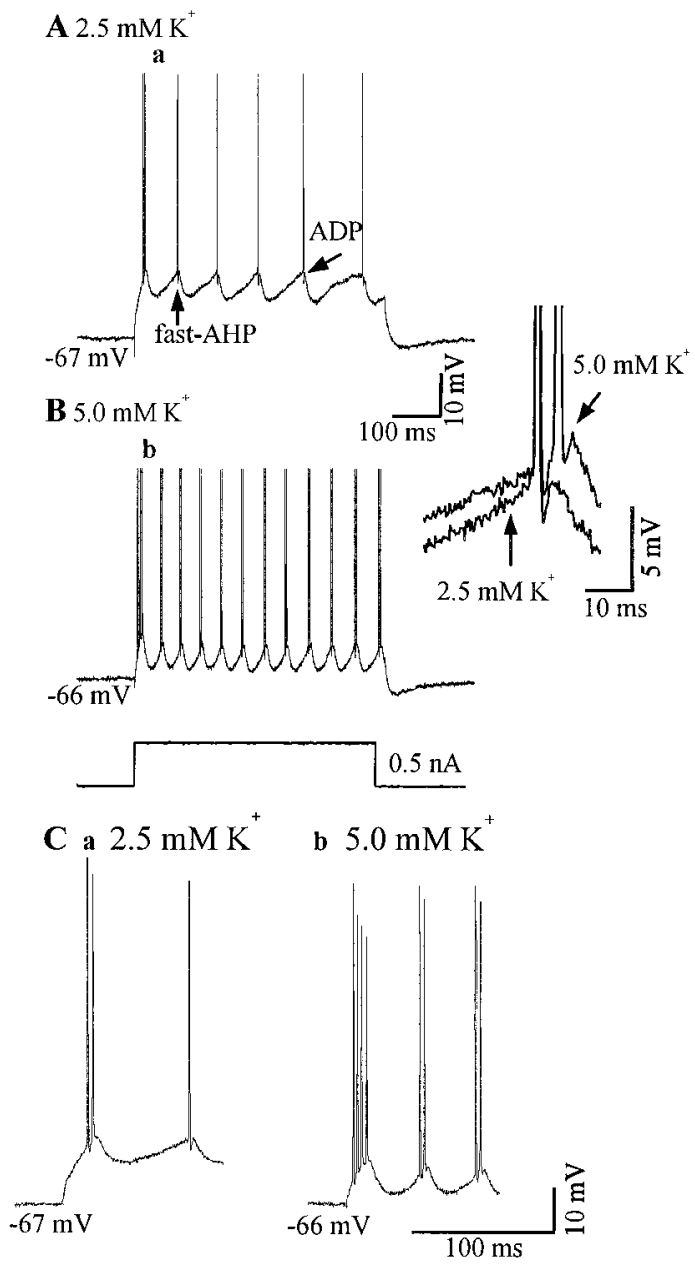

Figure 12. Raising extracellular $\mathrm{K}^{+}$induces bursting. Raising extracellular $\mathrm{K}^{+}$from $2.5 \mathrm{~mm}(a)$ to $5.0 \mathrm{~mm}(b)$ induced bursting to the same depolarizing current pulse (bottom trace, $+0.5 \mathrm{nA}$ ). Inset shows that in 5.0 $\mathrm{mM} \mathrm{K}^{+}$, the ADP reaches threshold for the generation of a second action potential. $C$, Magnification of the initial responses for $2.5 \mathrm{mM} \mathrm{K}^{+}(a)$ and $5.0 \mathrm{mM} \mathrm{K}^{+}(b)$ highlighting the transition from single spiking to bursting.

\section{Raising extracellular $\mathrm{K}^{+}$induces bursting}

The generation of bursts of action potentials appears to rely on the interplay of the fast AHP and ADP after action potential generation. To test this hypothesis, we increased $\left[\mathrm{K}^{+}\right]_{\mathrm{o}}$ to determine whether this may induce the generation of repetitive burst discharges (Fig. 12). Indeed, increasing $\left[\mathrm{K}^{+}\right]_{\mathrm{o}}$ from 2.5 to $5.0 \mathrm{~mm}$ changed the response of a subset of cortical neurons from the generation of a train of single action potentials to the generation of repetitive doublets of action potentials (Fig. 12). Comparison of the action potentials in the normal and high $\mathrm{K}^{+}$conditions revealed that spikes were broadened, the amplitude of the fast AHP was decreased, and the spike ADP became suprathreshold for the initiation of an additional action potential (Fig. 12, inset).

The raising of extracellular $\mathrm{K}^{+}$was effective in inducing repetitive doublet firing in five of six neurons tested, all of which had prominent ADPs. For three of these five neurons, current injections were also used to induce repetitive doublet firing. The pattern of action potential generation after current-induced alterations and those induced by raising $\left[\mathrm{K}^{+}\right]_{\mathrm{o}}$ were similar (data not shown).
A Control

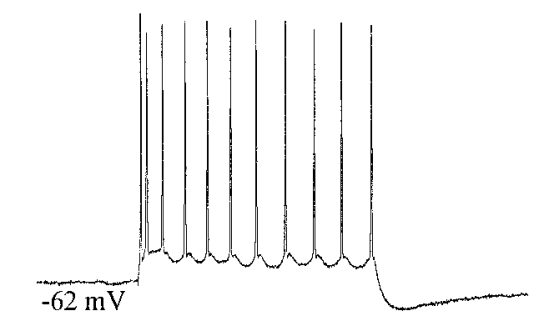

B $50 \mu \mathrm{M} \mathrm{ATX} \mathrm{II}$

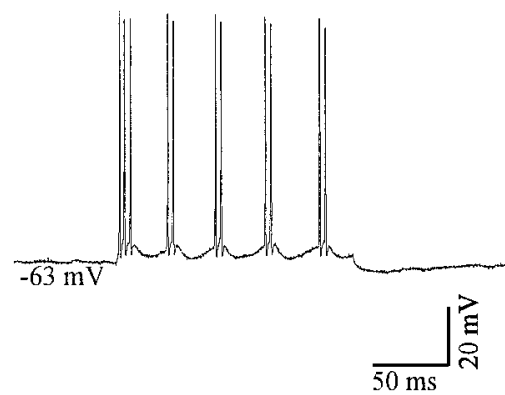

Figure 13. Potentiation of the persistent $\mathrm{Na}^{+}$current induces bursting. Local application of ATX II $(50 \mu \mathrm{M}$ in pipette) evoked bursting in response to a $120 \mathrm{msec}+0.5 \mathrm{nA}$ current pulse $(B)$. $A$ represents the response before ATX II application.

\section{Potentiation of the persistent $\mathrm{Na}^{+}$current induces bursting}

To examine whether modifications of the inactivation of $\mathrm{Na}^{+}$ currents could induce chattering, we applied the sea anemone toxin ATX II. This toxin reduces $\mathrm{Na}^{+}$channel inactivation but does not affect activation (Romey et al., 1976; Alsen, 1983). Local application of ATX II (50 $\mu \mathrm{M}$ in pipette) to neurons that exhibited relatively short duration action potentials and an ADP after each action potential resulted in the conversion of trains of single spikes to repetitive bursting (Fig. 13) $(n=4)$. In three of these cells, the intracellular injection of constant current (before ATX II application) also induced repetitive burst firing. The induction by ATX II was irreversible, unlike the above cases in which the bursting was only transitory, lasting for $20 \mathrm{sec}$ to $1 \mathrm{~min}$ after current induced bursting or only as long as $\mathrm{K}^{+}$was elevated.

\section{DISCUSSION}

Extracellular recordings in awake, behaving animals reveal that bursts of action potentials at rates of $>300 \mathrm{~Hz}$ are relatively common (Bair et al., 1994; Gray and di Prisco, 1997). These bursts may occur singly or in a repetitive manner, such as during the generation of gamma-frequency oscillations (Gray and Singer, 1989), and at least some of these bursts are generated through intrinsic membrane mechanisms (Calvin and Sypert, 1976; McCormick et al., 1985; Gray and McCormick, 1996; Steriade et al., 1998). The intrinsic generation of high-frequency $(>300 \mathrm{~Hz})$ bursts occurs in cat motor cortex pyramidal and nonpyramidal tract neurons (Calvin and Sypert, 1976; Baranyi et al., 1993; Steriade et al., 1998; Kitagawa et al., 1999), in superficial pyramidal neurons of the cat primary visual cortex (Gray and McCormick, 1996), in supragranular and infragranular pyramidal cells in cat association cortex (Steriade et al., 1998), in the somatosensory cortex of raccoon in vivo (Istvan and Zarzecki, 1994) and of cat in vitro (Kitagawa et al., 1999), and in the visual cortex of the ferret 
in vitro (present study). This pattern of high-frequency burst discharges has been termed chattering (Gray and McCormick, 1996), fast rhythmic bursting (Steriade et al., 1998), and noninactivating bursting (Baranyi et al., 1993).

\section{Ionic mechanisms of intrinsic burst generation in cortical neurons}

Previous studies of the ionic mechanisms of burst generation in cortical neurons have focused largely on low-frequency $(<300$ $\mathrm{Hz}$ ) burst firing in large layer $\mathrm{V}$ neocortical pyramidal cells or in hippocampal pyramidal neurons. These bursts appear as an allor-none discharge of two to five action potentials with each successive spike decreasing in amplitude and broadening in duration and may be generated by either the activation of a slow $\mathrm{Ca}^{2+}$ current in the dendrites (Helmchen et al., 1999; Schwindt and Crill, 1999) or the generation of a $\mathrm{Na}^{+}$-dependent spike afterdepolarization (Franceschetti et al., 1995; Azouz et al., 1996; Guatteo et al., 1996; Jensen et al., 1996).

Our present results strongly support the role of $\mathrm{Na}^{+}$, but not $\mathrm{Ca}^{2+}$, currents in the initiation of a spike afterdepolarization that is critical for the generation of high-frequency burst discharges in chattering neurons. Two important factors in the generation of high-frequency burst discharges were short duration action potentials, which allow the occurrence of high-frequency $(>300 \mathrm{~Hz})$ burst discharges, and the activation of a fast spike afterdepolarization that was large enough to reach spike threshold for the initiation of an additional action potential (Fig. 4). The intracellular injection of short-duration depolarizing current pulses did not generate burst discharges in these cells in an all-or-none fashion. The generation of a high-frequency burst required both the maintained depolarization of the cell with the intracellular current injection as well as the occurrence of an afterdepolarization. This result suggests that these cells may generate action potentials either singly, in response to a short-duration depolarizing postsynaptic potential, or in bursts, with varying numbers of action potentials, depending on the duration of the underlying synaptic depolarization. The number of spikes is limited, however, to typically four or five, owing to the activation of ionic currents that repolarize the membrane (Fig. 9).

\section{Calcium plays a minor role in burst generation}

The block of transmembrane $\mathrm{Ca}^{2+}$ currents with low $\mathrm{Ca}^{2+}$ and added $\mathrm{Mn}^{2+}$ did not block high-frequency burst firing in our experiments, indicating a nonessential role for transmembrane $\mathrm{Ca}^{2+}$ entry in the generation of these events. Similarly, the intracellular chelation of $\mathrm{Ca}^{2+}$ with BAPTA also did not block the generation of high-frequency burst discharges. However, this evidence is less strong because the chelation of intracellular $\mathrm{Ca}^{2+}$ may enhance burst firing in some cortical neurons, presumably through the removal of $\mathrm{Ca}^{2+}$-dependent inactivation of $\mathrm{Ca}^{2+}$ currents (Friedman and Gutnick, 1989).

This is not to say that $\mathrm{Ca}^{2+}$ plays no role in the generation of chattering. In fact when chattering cells were recorded in bathing solution without $\mathrm{Ca}^{2+}$ or with electrodes filled with BAPTA, there was an increase in the intraburst frequency and a decrease in the interburst frequency. Thus it appears that $\mathrm{Ca}^{2+}$ can modulate the interburst frequency of chattering cells (Fig. 14B).

\section{The activation of $\mathrm{a} \mathrm{Na}^{+}$current underlies bursting in chattering cells}

The activation of a $\mathrm{Na}^{+}$current plays an important role in burst generation in chattering cells, because replacement of $\mathrm{NaCl}$ with choline $\mathrm{Cl}$, the extracellular application of tetrodotoxin or phe-
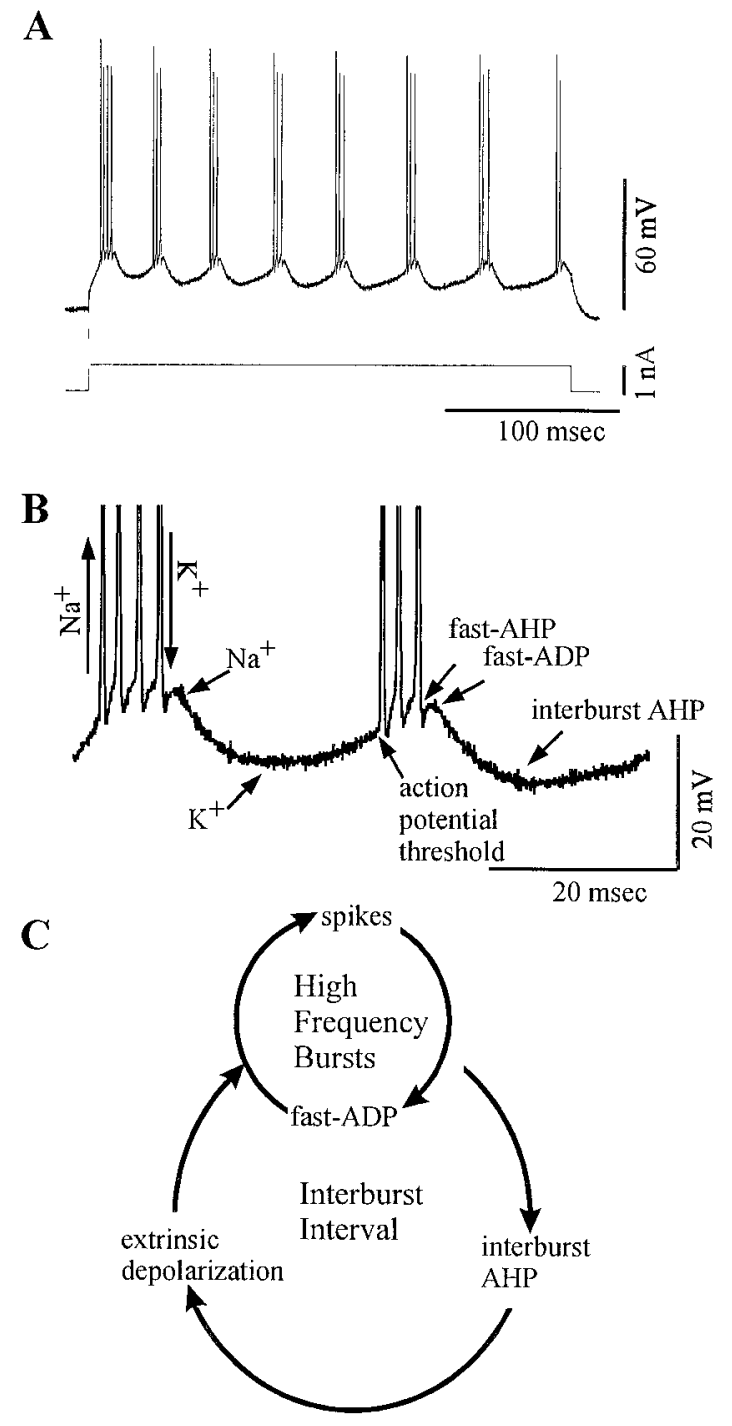

Figure 14. Summary of the proposed mechanisms for chattering. Repetitive high-frequency bursting in response to a depolarizing current pulse is typical of chattering cells in vitro $(A)$. Magnification of the bursts highlights the presence of fast AHPs after each action potential. Each burst is terminated by a $\mathrm{Na}^{+}$-dependent ADP that does not reach spike threshold $(B)$ and is followed by the interburst AHP. The high-frequency bursts that typify chattering cells result as an interaction between fast $\mathrm{Na}^{+}$spikes and a fast ADP; the interburst interval is governed by the rate at which the membrane repolarizes $(C$, interburst $A H P)$ and the amplitude of any extrinsic depolarizing influences.

nytoin, and the intracellular infusion of QX-314 all inhibited the fast spike afterdepolarization and bursting before inhibiting action potential generation (Franceschetti et al., 1995; Azouz et al., 1996). In addition, in our experiments, reduction of $\mathrm{Na}^{+}$current inactivation with the sea anemone toxin ATX II induced rhythmic high-frequency burst discharges.

One possibility is that chattering and the spike afterdepolarization are generated by the activation of a persistent $\mathrm{Na}^{+}$ current in the soma and/or dendrites. The persistent $\mathrm{Na}^{+}$current is activated rapidly (French et al., 1990; Kay et al., 1998), does not inactivate (Taylor, 1993), is active at membrane potentials close to spike threshold (Gilly and Armstrong, 1984; for review, see Crill, 1996), and is blocked by QX-314 before effects on the $\mathrm{Na}^{+}$ 
current underlying action potential generation (Stafstrom et al., 1985; Hu, 1991). Thus affecting $I_{\text {Nap }}$ even slightly could have significant effects on the spiking output of a neuron (Alzheimer et al., 1993a). A recent computational model of chattering suggested that the activation of $\mathrm{a} \mathrm{Na}^{+}$current in the dendrites, by the occurrence of action potentials in the initial segment or soma, could result in the spike afterdepolarization and therefore the generation of high-frequency burst discharges (Wang, 1999). In this mechanism, the depolarization provided by the activation of $\mathrm{Na}^{+}$currents in the dendrites provides a slow depolarization to the spike generating mechanism in the soma, thereby initiating an additional action potential. In this manner, the soma and dendritic $\mathrm{Na}^{+}$currents interact in somewhat of a "ping-pong" (reciprocal) mechanism for the generation of burst discharges.

\section{Factors influencing chattering in vitro}

The generation of rhythmic high-frequency burst discharges is not generally observed with the in vitro slice technique. Several possible variables may contribute to this, including the age and species of the animals used, the temperature and composition of the ionic medium, and the style of recording chamber (e.g., interface or submerged). We have not observed chattering cells in vitro in tissue from ferrets that are less than $\sim 4$ months of age. In rats, the action potential, the persistent $\mathrm{Na}^{+}$current, and the ability to generate bursts are not mature until $\sim 1$ month postnatally (McCormick and Prince, 1987; Huguenard et al., 1988; Alzheimer et al., 1993b; Franceschetti et al., 1993).

An additional important factor is likely to be the composition of the ionic medium. We observed a significantly higher number of chattering cells in medium containing $1.2 \mathrm{mM} \mathrm{Ca}^{2+}$, and recently we have also observed that lowering $\mathrm{Mg} 2+$ from $2.0 \mathrm{~mm}$ to a more physiological level of $1.0 \mathrm{~mm}$ and raising $\mathrm{K}^{+}$from 2.5 $\mathrm{mm}$ to a more physiological value of $3.5 \mathrm{~mm}$ also significantly enhances the incidence of chattering in vitro (our unpublished observations). Another important variable is likely the species of animal used, because chattering cells have not yet been observed in rodent cortex.

\section{Is chattering a cell type or a discharge mode?}

Our present results, and those of Kang and Kayano (1994), suggest that some cortical neurons may fire in both a "regular spiking" and a repetitive bursting mode similar to chattering. Neurons that we could induce to chatter exhibited relatively short-duration action potentials, a fast spike afterhyperpolarization, and a fast afterdepolarization (Fig. 10). The induction of fast rhythmic bursting with current injection is associated with a broadening of the action potential, a decrease in the amplitude of the fast AHP, and an increase in the ability of the ADP to activate additional spikes. In other studies, increasing extracellular $\mathrm{K}^{+}$(Jensen et al., 1994) and the application of ATX II (Mantegazza et al., 1998) have transformed single spiking neurons into ones that discharged bursts of action potentials to a depolarizing step pulse.

The critical factor in this transformation appears to be the reduction in the fast afterhyperpolarization, which then allows the ADP to reach spike threshold (Fig. 4). The reduction of the fast AHP could be caused by a decrease in the driving force of $\mathrm{K}^{+}$, perhaps from accumulation of $\mathrm{K}^{+}$in the pericellular space (Frankenhaeuser and Hodgkin, 1956). The slow reversion of the cell back to regular spiking then may represent the clearing of this excess $\mathrm{K}^{+}$. Alternatively, the fast AHP could reduce owing to changes in the $\mathrm{K}^{+}$channels themselves, such as in the voltage sensing mechanism. Another mechanism by which repetitive burst firing may be induced is through the enhancement of the $\mathrm{Na}^{+}$current underlying the afterdepolarization, such as through a decease in $\mathrm{Na}^{+}$channel inactivation (Fig. 13). Interestingly, the activation of muscarinic or glutamate metabotropic receptors can induce, or enhance the induction of, chattering (McCormick and Nowak, 1996).

Does mode switching occur naturally? It is not yet known whether neurons in vivo switch between regular spiking and rhythmic bursting, although a significant incidence of burst firing occurs in awake behaving animals (Otto et al., 1991), and increases in extracellular $\mathrm{K}^{+}$to $5.0 \mathrm{~mm}$ or greater can occur in the neocortex during sensory stimulation (Singer and Lux, 1975; Poolos et al., 1987). Importantly, epileptic seizures are associated with even higher levels of extracellular $\mathrm{K}^{+}$, suggesting that the induction of high-frequency bursting in cortical neurons may contribute to these events (Orkand, 1980; Pumain et al., 1987).

Are chattering cells actually regular spiking cells in the "chattering mode"? We have not observed chattering neurons, with either extracellular or intracellular recordings, to change to the regular spiking mode in the absence of stimulation or after hyperpolarization. This suggests that a subset of cortical neurons are persistent chatterers and therefore identified as chattering cells (Gray and McCormick, 1996), whereas others may merely be induced to discharge in the chattering mode.

\section{Functional consequences of burst discharges}

Many cortical synapses appear to have high failure rates (Allen and Stevens, 1994), and thus the fidelity of information transfer between presynaptic and postsynaptic elements can be relatively low (Allen and Stevens, 1994; Lisman, 1997). In contrast, with bursts of action potentials the probability of synaptic failure is reduced (Lisman, 1997; Rieke et al., 1997; Williams and Stuart, 1999). Mode switching from single to burst spiking might give the neuron the ability to dynamically regulate the information content of its spike train by modulating synaptic efficacy.

In vivo it has been demonstrated that bursts convey more information than single spikes (Cattaneo et al., 1981; Otto et al., 1991; Rieke et al., 1997). Additionally, in vivo populations of neurons can oscillate at $30-70 \mathrm{~Hz}$ in response to visual and other sensory stimuli (Gray and McCormick, 1996; Murthy and Fetz, 1996). The interburst frequency of chattering cells is in this frequency range, both in vivo (Gray and McCormick, 1996) and in vitro. Furthermore, it has been postulated that activation of neurons with horizontally projecting axons (Gilbert, 1992) works in concert with feedback connections (Munk et al., 1995) to synchronize the firing of different populations of neurons. Indeed, chattering cells possess axons that project horizontally through the gray matter and could form the anatomical basis for the observed synchronization. Thus, chattering cells are in an ideal position to act as synchronizers of dynamically coupled neuronal networks.

\section{REFERENCES}

Aghajanian GK, Rasmussen K (1989) Intracellular studies in the facial nucleus illustrating a simple new method for obtaining viable motoneurons in adult rat brain slices. Synapse 3:331-338.

Agmon A, Connors BW (1989) Repetitive burst-firing in the deep layers of mouse somatosensory cortex. Neurosci Lett 99:137-141.

Ahmed B, Anderson JC, Douglas RJ, Martin KA, Whitteridge D (1998) Estimates of the net excitatory currents evoked by visual stimulation of identified neurons in cat visual cortex. Cereb Cortex 8:462-476.

Allen C, Stevens CF (1994) An evaluation of causes for unreliability of synaptic transmission. Proc Natl Acad Sci USA 91:10380-10383. 
Alsen C (1983) Biological significance of peptides from Anemonia sulcata. FASEB J 42:101-108.

Alzheimer, C, Schwindt, PC, Crill, WE (1993a) Modal gating of $\mathrm{Na}^{+}$ channels as a mechanism of persistent $\mathrm{Na}^{+}$current in pyramidal neurons from rat and cat sensorimotor cortex. J Neurosci 13:660-673.

Alzheimer C, Schwindt PC, Crill WE (1993b) Postnatal development of a persistent $\mathrm{Na}^{+}$current in pyramidal neurons from rat sensorimotor cortex. J Neurophysiol 69:290-292.

Azouz R, Jensen MS, Yaari Y (1996) Ionic basis of spike afterdepolarization and burst generation in adult rat hippocampal CA1 pyramidal cells. J Physiol (Lond) 492:211-223.

Bair W, Koch C, Newsome W, Britten K (1994) Power spectrum analysis of bursting cells in area MT in the behaving monkey. J Neurosci 14:2870-2892.

Baranyi A, Szente MB, Woody CD (1993) Electrophysiological characterization of different types of neurons recorded in vivo in the motor cortex of the cat. I. Patterns of firing activity and synaptic responses. J Neurophysiol 69:1850-1864.

Brau ME, Nau C, Hempelmann G, Vogel W (1995) Local anesthetics potently block a potential insensitive potassium channel in myelinated nerve. J Gen Physiol 105:485-505.

Calvin WH, Sypert GW (1976) Fast and slow pyramidal tract neurons: an intracellular analysis of their contrasting repetitive firing properties in the cat. J Neurophysiol 39:420-434.

Cattaneo A, Maffei L, Morrone C (1981) Patterns in the discharge of simple and complex visual cortical cells. Proc R Soc Lond B Biol Sci B212:279-297.

Chagnac-Amitai Y, Luhmann HJ, Prince DA (1990) Burst generating and regular spiking layer 5 pyramidal neurons of rat neocortex have different morphological features. J Comp Neurol 296:598-613.

Chao TI, Alzheimer C (1995) Effects of phenytoin on the persistent $\mathrm{Na}+$ current of mammalian CNS neurones. NeuroReport 6:1778-1780.

Chen W, Zhang JJ, Hu GY, Wu CP (1996) Different mechanisms underlying the repolarization of narrow and wide action potentials in pyramidal cells and interneurons of cat motor cortex. Neuroscience 71:57-68.

Connors BW, Prince DA (1982) Effects of local anesthetic QX-314 on the membrane properties of hippocampal pyramidal neurons. J Pharmacol Exp Ther 220:476-481.

Crill WE (1996) Persistent sodium current in mammalian central neurons. Annu Rev Physiol 58:349-362.

Erisir A, Lau D, Rudy B, Leonard CS (1999) Function of specific K+ channels in sustained high-frequency firing of fast-spiking neocortical interneurons. J Neurophysiol 82:2476-2489.

Evarts EV (1962) Spontaneous discharge of single neurons during sleep and waking. Science 135:726-728.

Evarts EV (1964) Temporal patterns of discharge of pyramidal tract neurons during sleep and waking in the monkey. J Neurophysiol 27:152-171.

Franceschetti S, Buzio S, Panzica F, Avanzini G (1993) Expression of intrinsic bursting properties in neurons of mature sensorimotor cortex. Neurosci Lett 162:25-28.

Franceschetti S, Guatteo E, Panzica F, Sancini Wanke E, Avanzini G (1995) Ionic mechanisms underlying burst firing in pyramidal neurons: intracellular study in rat sensorimotor cortex. Brain Res 696:127-139.

Frankenhaeuser B, Hodgkin AL (1956) The after-effects of impulses in the giant nerve fibers of loglio. J Physiol (Lond) 131:341-376.

Frankenhaeuser B, Hodgkin AL (1957) The action of calcium on the electrical properties of squid axons. J Physiol (Lond) 137:218-244.

French CP, Sah P, Buckett KL, Gage PW (1990) A voltage-dependent persistent sodium current in mammalian hippocampal neurons. J Gen Physiol 95:1139-1157.

Friedman A, Gutnick MJ (1989) Intracellular calcium and control of burst generation in neurons of guinea-pig neocortex in vitro. Eur J Neurosci 1:374-381.

Gilbert CD (1992) Horizontal integration and cortical dynamics. Neuron 9:1-13.

Gilly WF, Armstrong CM (1984) Threshold channels: a novel type of sodium channel in squid giant axon. Nature 309:448-450.

Gray CM, McCormick DA (1996) Chattering cells: superficial pyramidal neurons contributing to the generation of synchronous oscillations in the visual cortex. Science 274:109-113.

Gray CM, di Prisco GV (1997) Stimulus-dependent neuronal oscillations and local synchronization in striate cortex of the alert cat. J Neurosci 17:3239-3253.
Gray CM, Singer W (1989) Stimulus-specific neuronal oscillations in orientation columns of cat visual cortex. Proc Natl Acad Sci USA 86:1698-1702.

Guatteo E, Franceschetti S, Bacci A, Avanzini G, Wanke E (1996) A TTX-sensitive conductance underlying burst firing in isolated pyramidal neurons from rat neocortex. Brain Res 741:1-12.

Hansen AJ (1985) Effect of anoxia on ion distribution in the brain. Physiol Rev 65:101-148.

Helmchen F, Svoboda K, Denk W, Tank DW (1999) In vivo dendritic calcium dynamics in deep-layer cortical pyramidal neurons. Nat Neurosci 2:989-996.

Hille B (1968) Charges and potentials at the nerve surface divalent ions and $\mathrm{pH}$. J Gen Physiol 51:221-236.

Hille B (1992) Ionic channels of excitable membranes. Sunderland, MA: Sinauer.

Horikawa K, Armstrong WE (1988) A versatile means of intracellular labeling: injection of biocytin and its detection with avidin conjugates. J Neurosci Methods 25:1-11.

Hu GY (1991) Effects of depolarization and QX-314 injection on slow prepotentials in rat hippocampal pyramidal neurons in vitro. Acta Physiol Scand 141:235-240.

Huguenard JR, Hamill OP, Prince DA (1988) Developmental changes in $\mathrm{Na}^{+}$conductance in rat neocortical neurons: appearance of a slowly inactivating component. J Neurophysiol 59:778-795.

Istvan PJ, Zarzecki P (1994) Intrinsic discharge patterns and somatosensory inputs for neurons in raccoon primary somatosensory cortex. J Neurophysiol 72:2827-2839.

Jensen MS, Azouz R, Yaari Y (1994) Variant firing patterns in rat hippocampal pyramidal cells modulated by extracellular potassium. J Neurophysiol 71:831-839.

Jensen MS, Azouz R, Yaari Y (1996) Spike after-depolarization and burst generation in adult rat hippocampal CA1 pyramidal cells. J Physiol (Lond) 492:199-210.

Kang Y, Kayano F (1994) Electrophysiological and morphological characteristics of layer VI pyramidal cells in the cat motor cortex. J Neurophysiol 72:578-591.

Kay AR, Sugimori M, Llinas R (1998) Kinetic and stochastic properties of a persistent sodium current in mature guinea pig cerebellar purkinje cells. J Neurophysiol 80:1167-1179.

Kitagawa H, Nishimura Y, Yamamoto T (1999) Synaptic excitability of the burst firing neurons in cat sensorimotor cortex in vitro. Brain Res 842:101-108

Lancaster B, Nicoll RA (1987) Properties of two calcium-activated hyperpolarizations in rat hippocampal neurones. J Physiol (Lond) 389:187-203.

Lisman JE (1997) Bursts as a unit of neural information: making unreliable synapses reliable. Trends Neurosci 20:38-43.

Llinas RR (1988) The intrinsic electrophysiological properties of mammalian neurons: insights into central nervous system function. Science 242:1654-1664.

Mantegazza M, Franceschetti S, Avanzini G (1998) Anemone toxin (ATX II)-induced increase in persistent sodium current: effects on the firing properties of rat neocortical pyramidal neurones. J Physiol (Lond) 507:105-116.

Mason A, Larkman A (1990) Correlations between morphology and electrophysiology of pyramidal neurons in slices of rat visual cortex. II. Electrophysiology. J Neurosci 10:1415-1428.

Mattia D, Kawasaki H, Avoli M (1997) In vitro electrophysiology of rat subicular bursting neurons. Hippocampus 7:48-57.

McCormick DA, Nowak L (1996) Possible cellular mechanisms for arousal-induced higher frequency oscillations: acetylcholine and ACPD induce repetitive burst firing in visual cortical neurons. Soc Neurosci Abstr 22:644.

McCormick DA, Pape HC (1990) Noradrenergic and serotonergic modulation of a hyperpolarization-activated cation current in thalamic relay neurones. J Physiol (Lond) 431:319-342.

McCormick DA, Prince DA (1987) Post-natal development of electrophysiological properties of rat cerebral cortical pyramidal neurones. J Physiol (Lond) 393:743-762.

McCormick DA, Connors BW, Lighthall JW, Prince DA (1985) Comparative electrophysiology of pyramidal and sparsely spiny stellate neurons of the neocortex. J Neurophysiol 54:782-806.

Munk MHJ, Nowak LG, Nelson JI, Bullier J (1995) Structural basis of cortical synchronization II. Effects of cortical lesions. J Neurophysiol 74:2401-2414. 
Murthy VN, Fetz EE (1996) Oscillatory activity in sensorimotor cortex of awake monkeys: synchronization of local field potentials and relation to behavior. J Neurophysiol 76:3949-3967.

Nathan T, Jensen MS, Lambert JDC (1990) The slow inhibitory postsynaptic potential in rat hippocampal CA1 neurones is blocked by intracellular injection of QX-314. Neurosci Lett 110:309-313.

Niesen C, Charlton MP, Carlen PL (1991) Postsynaptic and presynaptic effects of the calcium chelator BAPTA on synaptic transmission in rat hippocampal dentate granule neurons. Brain Res 555:319-325.

Orkand RK (1980) Extracellular potassium accumulation in the nervous system. FASEB J 39:1515-1518.

Otto T, Eichenbaum H, Wiener SI, Wible CG (1991) Learning-related patterns of CA1 spike trains parallel stimulation parameters optimal for inducing hippocampal long-term potentiation. Hippocampus 1:181-192.

Perkins KL, Wong RKS (1995) Intracellular QX-314 blocks the hyperpolarization-activated inward current $\mathrm{I}_{\mathrm{O}}$ in hippocampal CA1 pyramidal cells. J Neurophysiol 73:911-915.

Pineda JC, Waters RS, Foehring RC (1998) Specificity in the interaction of $\mathrm{HVAC} \mathrm{Ca}^{2+}$ channel types with $\mathrm{Ca}^{2+}$-dependent AHPs and firing behavior in neocortical pyramidal neurons. $J$ Neurophysiol 79:2522-2534.

Poolos NP, Mauk MD, Kocsis JD (1987) Activity-evoked increases in extracellular potassium modulate presynaptic excitability in the CA1 region of the hippocampus. J Neurophysiol 58:404-416.

Pumain R, Kurcewicz I, Louvel J (1987) Ionic changes induced by excitatory amino acids in rat cerebral cortex. Can J Physiol Pharmacol 65:1067-1077.

Raman IM, Bean BP (1997) Resurgent sodium current and action potential formation in dissociated cerebellar Purkinje neurons. J Neurosci 17:4516-4526.

Rieke F, Warland D, van Steveninck RdR, Bialek W (1997) Spikes exploring the neural code. MIT Press, Cambridge, MA.

Romey G, Abita JP, Schweitz H, Wunderer G, Lasdunski M (1976) Sea anemone toxin: a tool to study molecular mechanisms of nerve conduction and excitation-secretion coupling. Proc Natl Acad Sci USA 73:4055-4059.

Schwindt P, Crill WE (1999) Mechanisms underlying burst and regular spiking evoked by dendritic depolarization in layer 5 cortical pyramidal neurons. J Neurophysiol 81:1341-1354.

Schwindt PC, Spain WJ, Crill WE (1992) Effects of intracellular calcium chelation on voltage-dependent and calcium-dependent currents in cat neocortical neurons. Neuroscience 47:571-578.
Segal MM, Douglas AF (1997) Late sodium channel openings underlying epileptiform activity are preferentially diminished by the anticonvulsant phenytoin. J Neurophysiol 77:3021-3034.

Singer W, Lux HD (1975) Extracellular potassium gradients and visual receptive fields in the cat striate cortex. Brain Res 96:378-383.

Snider RK, Kabara JF, Roig BR, Bonds AB (1998) Burst firing and modulation of functional connectivity in cat striate cortex. J Neurophysiol 80:730-744.

Stafstrom CE, Schwindt PC, Chubb MC, Crill WE (1985) Properties of persistent sodium conductance and calcium conductance of layer $\mathrm{V}$ neurons from cat sensorimotor cortex in vitro. J Neurophysiol 53:153-170.

Steriade M, Timofeev I, Durmuller N, Grenier F (1998) Dynamic properties of corticothalamic neurons and local circuit interneurons generating fast rhythmic $(30-40 \mathrm{~Hz})$ spike bursts. J Neurophysiol 79:483-490.

Storm JF (1990) Potassium currents in hippocampal pyramidal cells. Prog Brain Res 83:161-187.

Stuart GJ, Sakmann B (1994) Active propagation of somatic action potentials into neocortical pyramidal cell dendrites. Nature 367:69-72.

Stuart GJ, Spruston N, Sakmann B, Hausser M (1997) Action potential initiation and backpropagation in neurons of the mammalian CNS. Trends Neurosci 20:125-131.

Taylor CP (1993) $\mathrm{Na}^{+}$currents that fail to inactivate. Trends Neurosci 16:455-460.

Traub RD, Jefferys JGR, Miles R, Whittington MA, Toth K (1994) A branching dendritic model of a rodent CA3 pyramidal neurone. J Physiol (Lond) 481:79-95.

Wang XJ (1999) Fast burst firing and short-term synaptic plasticity: a model of neocortical chattering neurons. Neuroscience 89: 347-362.

Wang Z, McCormick DA (1993) Control of firing mode of corticotectal and corticopontine layer $\mathrm{V}$ burst-generating neurons by norepinephrine, acetylcholine, and 1S,3R-ACPD. J Neurosci 13:2199-2216.

Williams SR, Stuart GJ (1999) Mechanisms and consequences of action potential burst firing in rat neocortical pyramidal neurons. J Physiol (Lond) 521:467-482.

Wong RKS, Stewart M (1992) Different firing patterns generated in dendrites and somata of CA1 pyramidal neurones in guinea-pig hippocampus. J Physiol (Lond) 457:675-687.

Zhang L, Krnjevic K (1988) Intracellular injection of $\mathrm{Ca}^{2+}$ chelator does not affect spike repolarization of cat spinal motoneurons. Brain Res 462:174-180. 